\title{
Addressing Stem Cell Therapeutic Approaches in Pathobiology of Diabetes and Its Complications
}

\author{
Bou-Yue Peng, ${ }^{1,2}$ Navneet Kumar Dubey, ${ }^{3,4}$ Viraj Krishna Mishra, ${ }^{5}$ Feng-Chou Tsai, ${ }^{6}$ \\ Rajni Dubey, ${ }^{7}$ Win-Ping Deng $\left(\mathbb{D},{ }^{1,8,9}\right.$ and Hong-Jian Wei ${ }^{8}{ }^{8,10}$ \\ ${ }^{1}$ School of Dentistry, College of Oral Medicine, Taipei Medical University, Taipei City 110, Taiwan \\ ${ }^{2}$ Department of Dentistry, Taipei Medical University Hospital, Taipei City 110, Taiwan \\ ${ }^{3}$ Ceramics and Biomaterials Research Group, Advanced Institute of Materials Science, Ton Duc Thang University, \\ Ho Chi Minh City, Vietnam \\ ${ }^{4}$ Faculty of Applied Sciences, Ton Duc Thang University, Ho Chi Minh City, Vietnam \\ ${ }^{5}$ Applied Biotech Engineering Centre (ABEC), Department of Biotechnology, Ambala College of Engineering and Applied Research, \\ Ambala, India \\ ${ }^{6}$ Department of Stem Cell Research, Cosmetic Clinic Group, Taipei City 110, Taiwan \\ ${ }^{7}$ Graduate Institute of Food Science and Technology, National Taiwan University, Taipei City 106, Taiwan \\ ${ }^{8}$ Stem Cell Research Center, College of Oral Medicine, Taipei Medical University, Taipei, Taiwan \\ ${ }^{9}$ Graduate Institute of Basic Medicine, Fu Jen Catholic University, New Taipei City 242, Taiwan \\ ${ }^{10}$ School of Dental Technology, College of Oral Medicine, Taipei Medical University, Taipei City 110, Taiwan
}

Correspondence should be addressed to Win-Ping Deng; wpdeng@tmu.edu.tw and Hong-Jian Wei; hjwei@tmu.edu.tw

Received 28 January 2018; Revised 19 April 2018; Accepted 27 May 2018; Published 25 June 2018

Academic Editor: Érika B. Rangel

Copyright (c) 2018 Bou-Yue Peng et al. This is an open access article distributed under the Creative Commons Attribution License, which permits unrestricted use, distribution, and reproduction in any medium, provided the original work is properly cited.

\begin{abstract}
High morbidity and mortality of diabetes mellitus (DM) throughout the human population is a serious threat which needs to be addressed cautiously. Type 1 diabetes mellitus (T1DM) and type 2 diabetes mellitus (T2DM) are most prevalent forms. Disruption in insulin regulation and resistance leads to increased formation and accumulation of advanced end products (AGEs), which further enhance oxidative and nitrosative stress leading to microvascular (retinopathy, neuropathy, and nephropathy) and macrovascular complications. These complications affect the normal function of organ and tissues and may cause life-threatening disorders, if hyperglycemia persists and improperly controlled. Current and traditional treatment procedures are only focused on to regulate the insulin level and do not cure the diabetic complications. Pancreatic transplantation seemed a viable alternative; however, it is limited due to lack of donors. Cell-based therapy such as stem cells is considered as a promising therapeutic agent against DM and diabetic complications owing to their multilineage differentiation and regeneration potential. Previous studies have demonstrated the various impacts of both pluripotent and multipotent stem cells on DM and its micro- and macrovascular complications. Therefore, this review summarizes the potential of stem cells to treat DM and its related complications.
\end{abstract}

\section{Introduction}

The diabetes mellitus (DM), one of the most prevalent noncommunicable disease, is characterized by hyperglycemia leading to the development of severe life-threatening complications [1,2]. Recent decades have witnessed a sudden increase of diabetes throughout the world, in spite of numerous efforts made to control to outspread of this metabolic disorder. Currently, type 1 diabetes mellitus (T1DM) and type 2 diabetes mellitus (T2DM) are the most prevalent type of diabetes. The T1DM, which is also known as insulindependent DM, is caused due to impairment in regulation of blood glucose by absolute destruction of insulinproducing $\beta$-cells, whereas insufficient or no response to insulin is attributed to the pathogenesis of T2DM. The International Diabetes Federation (IDF) reported that the number 


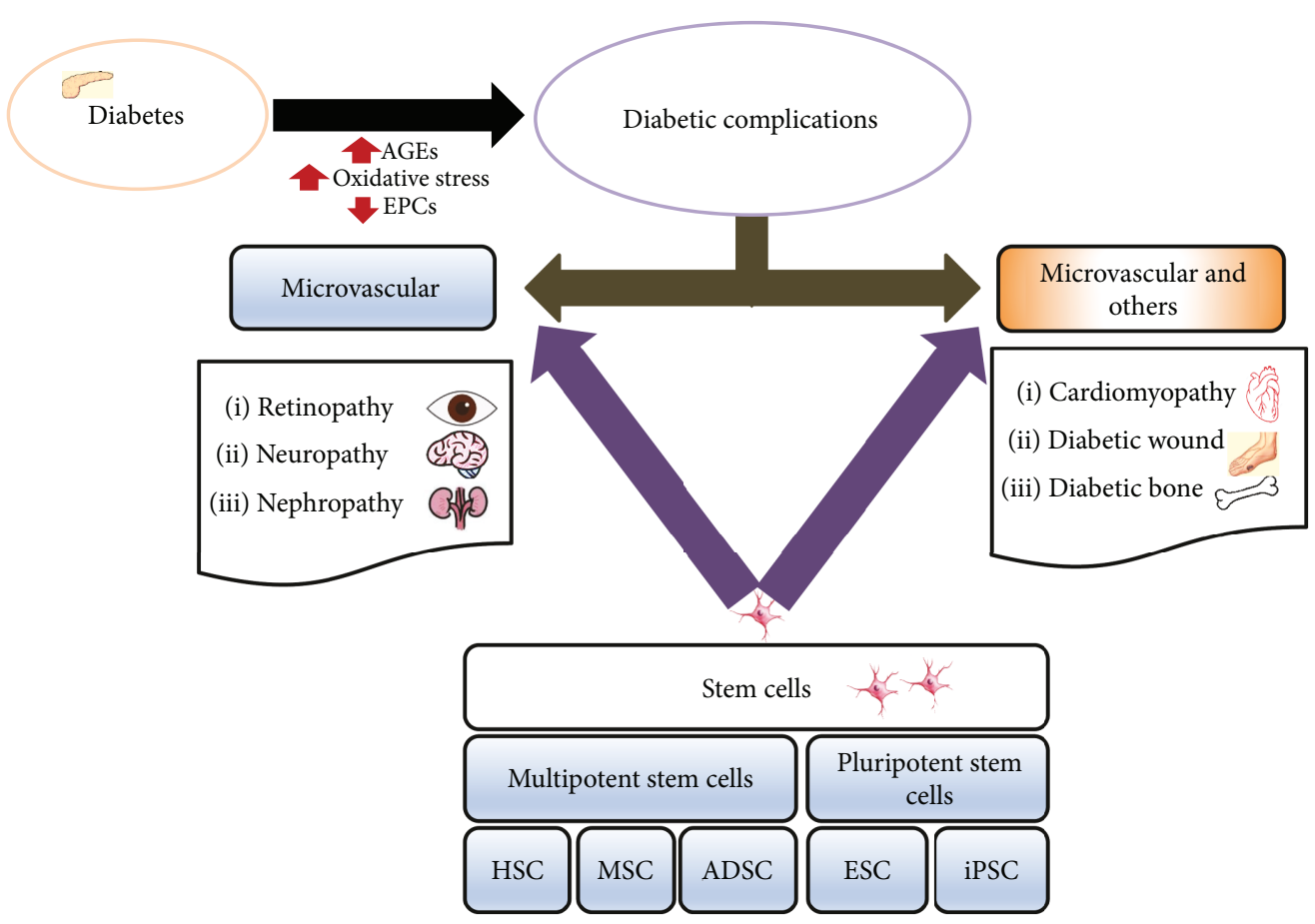

FIGURE 1: Schematic overview of stem cell therapy in diabetic complications. AGEs: advanced glycated end products; EPCs: epithelial progenitor cells; MSC: mesenchymal stromal cells; HSCs: hematopoietic stem cells; ADSC: adipose-derived stem cells; ESCs: embryonic stem cells; iPSCs: induced pluripotent stem cells.

of diabetic population will increase from 415 million in 2015 to 642 million by 2040 [2]. Of note, any defect in insulin regulation in blood triggers the in metabolic disorders of carbohydrate, fat, and protein leading to a condition of hyperglycemia [3]. Insulin secretion is mainly stimulated by glucose; however, other factors such as amino acids, fatty acids, acetylcholine, pituitary adenylate cyclase-activating polypeptide (PACAP), glucose-dependent insulinotropic polypeptide (GIP), and glucagon-like peptide-1 (GLP-1) also participate in regulating the metabolism of their respective biomolecules [4]. The thirst, polydipsia, weight loss, polyuria, and blurred vision are some common symptoms of diabetes; in severe cases, hyperglycemia along with ketoacidosis or nonketotic hyperosmolar conditions are prevalent [4].

Currently, diabetic retinopathy, nephropathy, and neuropathy are the major reported complications. The other complication also includes foot ulcer $[3,5]$. These complications have been reported to mediate via advanced glycations end products (AGEs), which mainly are the posttranscriptional modified proteins or lipids, and might be excessively synthesized during hyperglycemic conditions or present in the diet. These high levels of AGE also disrupt the defense mechanisms and assist in the destruction of $\beta$-cells [6]. 1Specifically, AGEs bind to their multiligands, known as a receptor of advanced glycation end products (RAGE), which activates different kinase and NADPH oxidase leading increased levels of ROS and further promotes the synthesis of more AGEs, thereby triggering cell-damaging mechanisms [7-9]. Notably, the AGEs not only destroy insulinproducing cells but also develop insulin resistance, a major symptom of T2DM [10].
It is well-known that the exercise and diet control are helpful to manage glucose level at initial stage [11]. The use of therapeutic insulin and other external hypoglycemic agents have also been employed to control the glucose level in blood, yet they are not capable enough to mimic the natural activity of endogenous insulin and may result in a hypoglycemic coma $[12,13]$. The other therapeutic approach is transplantation of pancreas or islet cells; however, this approach is limited due to the lack of donors and surgical and postsurgical complexities associated with therapy [14].

In general, stem cell is a population of cells defined by its ability to indefinitely expand, self-renew, and undergo asymmetric divisions to produce progeny cells committed to specific differentiation lineages [15]. Embryonic stem cells, a pluripotent cell derived from the inner cell mass of a blastocyst, are capable of generating almost every cell types of the body but are unable to form an entire organism. Multipotent stem cells reside within various niches in the body and are limited to differentiating into specialized cell types of their tissue of origin such as mesenchymal stem cells and hematopoietic stem cells [16]. Stem cells are important for living organisms due to their functions of homeostatic tissue maintenance and replacing dysfunctional and senescent cells. Given their remarkable regenerative capacities, stem cells are being applied in treatments for various diseases as a novel potential therapeutic intervention, which is also referred to as regenerative medicine (Figure 1 ). In previous years, the role of stem cells has been extensively studied for their therapeutic potential to treat diabetic pathology and related complications. Therefore, this article reviewed the possibilities of stem cell therapies in diabetes and its associated complications. 


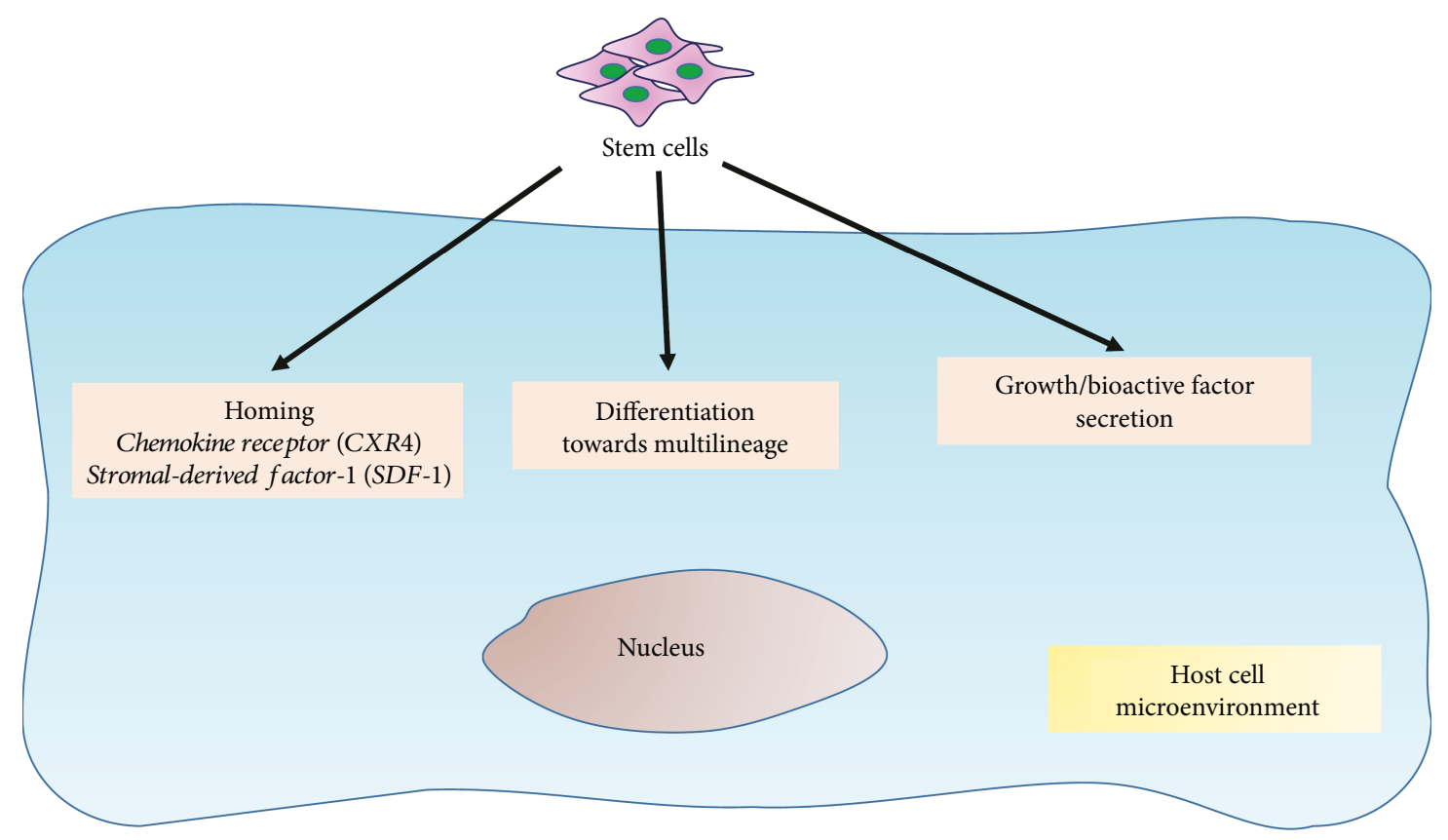

FIgURE 2: The possible mechanistic insight of therapeutic action of stem cells. During repair and regeneration, the transplanted MSC exhibit three modes of action, including homing, multilineage differentiation, and secretion of growth/bioactive factors.

\section{Stem Cells in Treatment of Diabetes}

Transplantation of insulin-producing cells [17] has paved the path to stem cell-based regeneration of insulin-secreting pancreatic $\beta$-cells [18]. Stem cells are unspecialized having the potential to regenerate and differentiate into specialized cells such as myocyte, hepatocyte, leukocyte, lymphocytes, erythrocytes, muscles, and nerve cells under proper environmental condition and signal [19]. On the basis of cell source, stem cells are generally classified as embryonic stem cells (ESCs) or adult stem cells (ASC). However, stem cells are also classified on the basis of origin, potential methods of derivations, and so on [19]. ESCs or pluripotent stem cells are isolated from inner cell mass of the blastocyst and have the potential to differentiate in different germ cell lines. However, the ethical issues make it very difficult to explore its potential to regenerate insulin-secreting cells. Notably, ASCs are multipotent stem cells and have the capacity to differentiate into only fewer cell types $[17,19]$. ASC such as hematopoietic stem cell (HSC) not only multiply itself but also develop into blood cells, whereas mesenchymal stem cells (MSCs) trigger the generation of fat, bone, and cartilage. ASC also helps in repair and replacement of damaged tissues along with developments of the central nervous system and muscle cells. The therapeutic potential of stem cells may be ascribed to three major embodied mechanisms of action (Figure 2). First, the systemically administered stem cells undergo "homing" which further migrate to the site of injury possibly due to chemoattraction mediated by cell surface receptors such as the chemokine receptors. Although the exact mechanism of stem cells and endothelial interaction at the target site is not well established, the integrins and selectins have been suggested to mediate such interactions $[20,21]$. The stem cell transmigration to the focal point of injury occurs across the endothelium through vascular cell adhesion molecule 1 (VCAM-1) and G-protein-coupled receptor signaling [22]. Secondly, the transplanted stem cell may undergo differentiation into multiple cell types, which after local engraftment can replace damaged tissues and induce restoration of their function $[23,24]$. Thirdly, stem cell may also secrete growth/bioactive factors, which may potentially positively influence both local as well as systemic physiological processes [25].

\section{Stem Cell-Derived Secretome in Organ Repair and Regeneration}

Regeneration and repair activities of stem cells depend on their differentiation potential to replace the damaged or injured tissues [26]. Recent in vivo studies have established the fact that most of the transplanted MSCs are cleared rapidly from the in vivo microenvironment, thus limiting the regenerative therapeutic potential of stem cell differentiation to direct organ repair [20]. Therefore, their paracrine and immunomodulatory function of MSCs seems more effective through cellular communication without physical contact between cells, along with secreted trophic factors, extracellular RNAs, and miRNA which leads to cellular modulation, thereby triggering change in the microenvironment [21]. Various studies have documented the role of secretory factors of MSCs in tissue repair and regeneration via regulating inflammatory and allogenic immune response $[23-25,27]$. It is clearly evident from recent reports that MSCs release soluble paracrine factors which regulate cellular proliferation, migration, differentiation, immunomodulation, and anti-inflammatory response through p38 MAPK, Akt, STAT-3, and TNF receptor pathways [28]. Stem cellspecific secretome includes the extracellular molecules such 


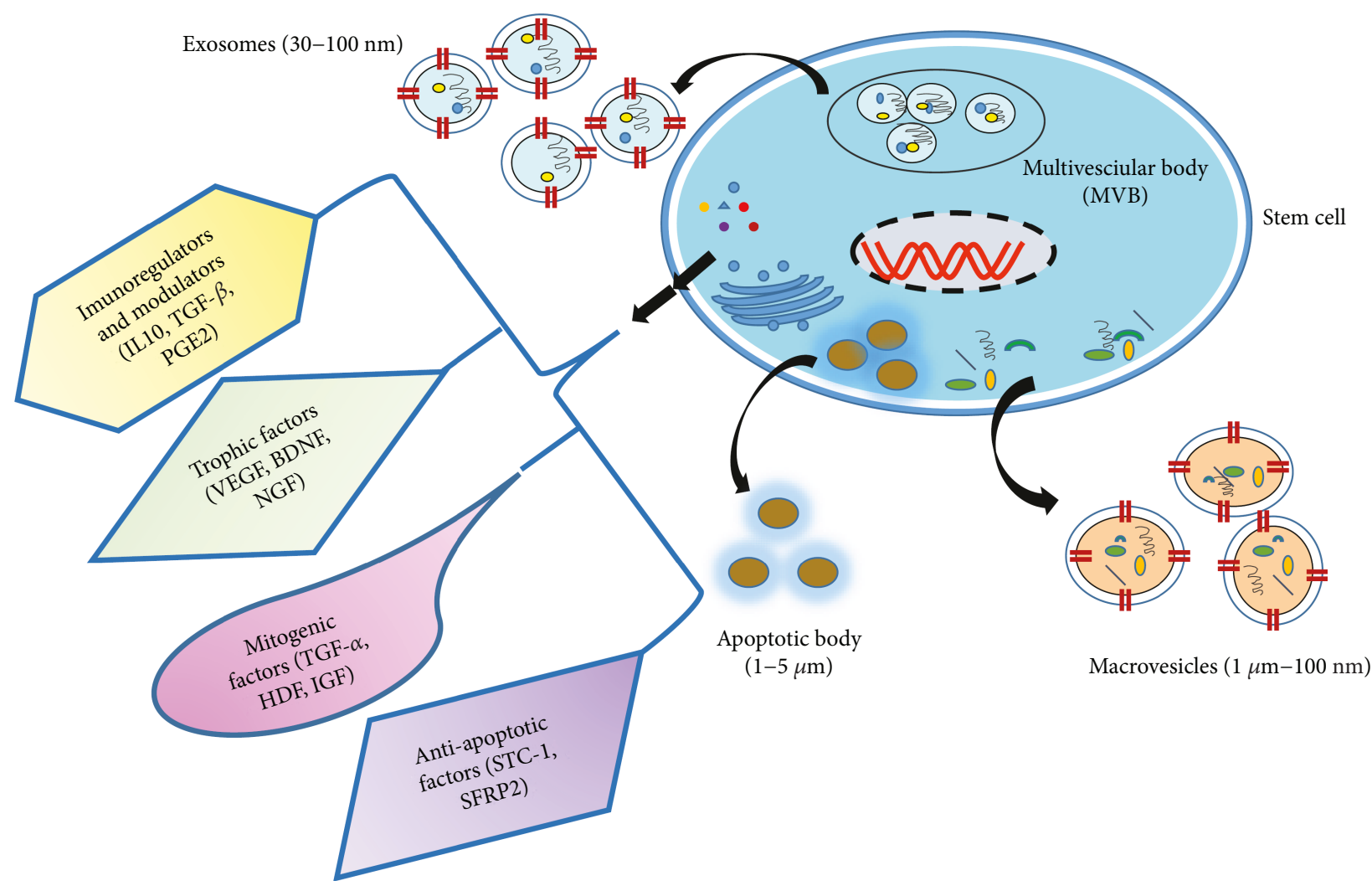

FIGURE 3: Mesenchymal stem cell-derived secretome and extracellular vesicles. IL: interleukin; TGF- $\beta$ : transforming growth factor beta; PGE2: prostaglandins E2; VEGF: vascular endothelial growth factor; BDNF: brain-derived neurotrophic factor; NGF: nerve growth factor; HGF: hepatocyte growth factor; IGF: insulin-derived growth factor; STC-1: stanniocalcin-1; SFRP2: secreted frizzled-related protein 2.

as extracellular vesicles (EVs), soluble proteins (e.g., chemokines, cytokines, and growth factors), lipids, and free nucleic acids $[29,30]$. These EVs are produced by internal budding and when released into cellular microenvironment promotes regeneration of injured/damaged cells similar to stem cells after endocytosis; this regeneration procedure is mediated by receptor-ligand interaction, fusion or transfer of proteins, and nucleic acids or miRNA [31-34]. Based on their physical characteristics, EVs are further categorized among exosomes, apoptotic bodies, and microvesicles (MVs) (Figure 3) [35]. Exosomes are made up of spherical bi-lipid layer ranging from $30-100 \mathrm{~nm}$ in size. These membrane vesicles are released by various cells and considered as critical component for cellular communications, and in altering cellular signaling has rendered it an interesting candidate in regenerative therapy [36]. Exosomes promote specific interaction with targeted tissues/cells along with the disposal of unwanted proteins, antigen presentation, genetic exchange, immune responses, angiogenesis, inflammation, tumor metastasis, and spreading of pathogens or oncogenes $[28,37,38]$. Furthermore, apoptotic bodies are released from cells undergoing programmed death as blebs of $1-5 \mu \mathrm{m}$ in diameter [39]. Besides these secretomes, the expression of factors such as vascular endothelial growth factor (VEGF), fibroblast growth factor-2 (FGF-2), hepatocyte growth factor (HGF), insulin-derived growth factor-1 (IGF-1), and thymosin B4 (TB4) is also released and is regulated by Akt signaling [40]. Interestingly, the increase in expression level of these factors has been observed under hypoxic conditioned medium. The increased production of VEGF in MSCs under normoxia or hypoxia has been found to be associated with STAT3 and p38 MAPK signaling pathways $[28,41]$, whereas in adult rat bone marrow multipotent progenitor cells (rMAPCs), JAK2/STAT3 signaling pathways have been ascribed [42]. Moreover, another study suggests that transforming growth factor- $\alpha$ - (TGF- $\alpha$-) induced VEGF production is associated with MEK and PI3-K signaling pathways in homogenous human BM-MSCs [43]. These observations indicate the varying signaling pathways are associated with VEGF production in different species [28]. Besides, the expression of TGF- $\beta 1$ in rat MAPCs has also been linked with STAT3 pathway [42]. TNF receptor (TNFR) and associated signaling pathways also plays a critical role in expression of paracrine factors such as VEGF, TNF, cytokines, and IL-6 $[28,44]$. It has also been reported that the production of HGF in human MSCs is closely associated with TNF and TGF$\alpha$ /epidermal growth factor (EGF) receptors and MEK, p38, and PI-3K signaling pathways [45], where the TNF receptor 1 played role in decrease of HGF, when stimulated with TGF- $\alpha$ and TNF- $\alpha$. A comparative study of paracrine factor profile of swine and human bone marrow MSCs showed that both cell cultures produced similar factors including VEGF and endothelin, along with other different paracrine factors under various conditions, which indicate that secretion of paracrine factors varies according to the species $[28,46]$. Apart from this, the age also impacts proliferation rate of 
MSCs and their secretome level of paracrine factors. In a recent study, p38 and ERK signaling pathways seemed to be associated with cytokine and growth factors in neonatal BM-MSCs [47]. Along with the abovementioned factors, the gender [48, 49], disease status [50, 51], and environmental factors also significantly influence the type and level of secretory factors of MSCs [28].

Homeostasis, cell development, and cell repair/regeneration/survival are mediated by membrane protein and cell adhesion biomolecules (integrins, tetraspanins, and cadherins) which direct receptor-mediated cellular communication [52, 53], whereas coupling of cellular cytoplasm is mediated by gap junctions [21, 54, 55]. Stem cells lack gap junction; however, differentiated cells may communicate through gap junctions. This was evidenced in a report in which BM-MSCs were able to differentiate into cardiac cells via their communication to near myocytes through gap junction [55, 56]. Besides, tunneling nanotubes (TNTs) are a newly explored actin-based elements involved in long distance-based cellular communication $[57,58]$, leading to tissue developments and regeneration [21, 59].

\section{Stem Cells Therapy in T1DM}

Insulin-secreting $\beta$-cells become nonfunctional in T1DM, and this condition primarily arises due to autoimmune destruction of cells causing hyperglycemia. Traditional insulin therapy assists to control blood glucose level; however, it has proven ineffective in the long-term. Islet transplantation therapy is limited due to the availability of pancreatic cells, cell rejection, use of immunosuppressive drugs, and other complexities $[17,60]$. These limitations could be avoided through stem cell therapies, owing to their very low immunogenic potential, immune-privileged, and immunomodulating properties [61-66]. Stem cells are also prone to genetic modification, through which the desired MHC complex may be introduced to control chance of immune rejections [67]. Furthermore, MSC has also been reported for their role in inhibition of T-cell proliferation, development of dendritic cells (DCs), and B-cell proliferation $[63,64,68]$. These reports are indicative of the immunosuppressive role of stem cells in transplantation therapy; however, more studies are required to establish their clinical significance.

In recent years, stem cells are emerging as a potential candidate for efficacious treatment for T1DM as these cells are capable to differentiate into mature $\beta$-cells in presence of required signals $[12,69]$. The immunomodulation properties of stem cells can be helpful to control a balance between $\beta$ cell destruction and their regeneration [70]. Mouse ESCs (mESCs) have been widely studied and reported to promote the differentiation of insulin-producing cells under induced conditions to avoid ethical conflicts. ESC controls selfrenewal by regulating the expression of different transcription factors such as Oct4, Sox2, and Nanog in presence of suitable medium [71]; germ cell nuclear factor (GCNF) and phosphoinositide kinase inhibitors catalyze the differentiation of specific functional cells. The designed media and transcription factors (Pax4 or Pdx-1) are reported for their potential to generate insulin-secreting cells [71-75]. Human
ESC (hESC) has been demonstrated to differentiate into functional $\beta$-cells in vivo [76]. However, the regulation of differentiation, teratoma formation, risk of viral infection, transplantation rejection, and ethical issues are still major bottlenecks to utilize it as a potential therapy.

iPSCs are the new alternatives of ESCs to avoid ethical concerns. iPSCs are mainly somatic cells which are reprogrammed to pluripotency. Though the traditional method of generating iPSCs are controversial, the iPSCs developed by Takahashi and Yamanaka have accelerated their use for generation of functional cells; in particular, the mouse and human fibroblasts have already been reprogrammed into pluripotent cells by using Oct3/4, Sox2, c-MYC/Lin28, and Nanog/Klf4 transcription factors [77, 78]. Miyazaki et al. also reprogrammed cancerous cells into induced pluripotent cells using the same transcription factors [79]. Kim et al. suggested that somatic cells which express any of the transcription factors required for induction of pluripotency will reduce the requirement of complete transcription factors [80]. For insulin regulation, mouse fibroblast cells have also been induced into pluripotent stem cells, which were further triggered to differentiate into insulin-producing cells for insulin regulation [81]. The potential of iPSCs in diabetes treatment is promising; however, the chances of tumor formation and immune response to transplantation need to be critically evaluated [70].

Adult stem cells such as hepatic stem cells, bone marrowhematopoietic stem cells (BM-HSCs), and mesenchymal stromal cells (MSCs) derived from the bone marrow and umbilical cord blood (UCB) and adipose tissue-derived MSCs (ADSCs) have been explored for their potential to generate insulin-producing cells. The endodermal nature of pancreatic cells makes hepatic stem cells a prospective stem cell source for therapeutic use. In various studies study, Pdx-1 was used to induce growth of $\beta$-cell precursors from hepatic tissues $[69,72,82,83]$. Mouse and human hepatic stem cells were differentiated into insulin-secreting $\beta$-like cells and used to overcome the condition of hyperglycemia [84]. The application of hepatic stem cells to induce the regeneration of insulin-producing cells is promising; however, further extensive research is required to establish the protocols for clinical application. Since MSCs have the potential to differentiate into pancreatic cells as well as to heal damaged cells, these have been exploited in treatment of T1DM [85]. BMMSCs are also able to promote graft acceptance and reduce autoimmunity [70, 86-88]. However, BM-MSCs' potential for stem cell therapy is limited by lack of standardized methods, difficulty in in vivo differentiation, and the possibility of tumor induction [70]. ADSCs are closely similar to the BMSCs and clinically accepted for their therapeutic potential due to ease of isolation with abundant cell numbers. The ADSCs have also been successfully used to counter type 1 diabetes in mice, and its potential to counteract the graft rejection response enhances the chance of success of T1DM therapy [70, 89-91].

\section{Stem Cell Therapy in T2DM}

Insulin resistance and a decrease in insulin production are the characteristics of T2DM. Conventional treatment 
approach includes using external insulin and use of oral antidiabetic drugs [92]. However, the regular use of in vitro insulin makes T2DM patients insulin resistant and contemporary therapy does not address this complication [93]. Transplantation of islet cells was once considered as a promising therapeutic approach; however, this approach is not common due to lack of donors, ethical conflict, and risk of immunogenicity. Regeneration and multipotent potential of stem cells make it an integral candidate for cell-based therapy. Stem cells such as BMSCs, ADSCs, ESCs, and iPSCs are able to differentiate into insulin-producing cells resulting in an increase in insulin level in patients under defined conditions and well-established procedures [94, 95]. Intrapancreatic autologous stem cell injection under hyperbaric oxygen condition regulates glycemic condition and insulin level [96]. Similar results were also reported when autologous bone marrow-derived stem cells were intra-arterially injected [97]. MSCs have improved islet function and controlled insulin resistance in T2DM. Various trials are under clinical phase I and II, however, only a few of them are based on random and placebo-controlled [92]. Moreover, the establishment of the exact pathway in stem cell-based treatment of T2DM still needs to be well established.

\section{Stem Cells in Diabetic Complications}

Diabetes not only disrupts the blood glucose regulations but also alters the metabolism in long run if poorly managed. As a result, micro- and macrovascular complications occur [98-100]. The microvascular complications arise due to impairment in small blood vessels under chronic hyperglycemic milieu. Some of these complications are diabetic retinopathy, neuropathy, and nephropathy, whereas the macrovascular complication is caused by damage to arteries leading to cardiovascular disease (CVD), coronary artery disease (CAD), peripheral arterial disease, myocardial infarction (MI), and stroke. Diabetes-associated disorders like osteoporosis, osteoarthritis, foot ulcers, and diabetic cardiomyopathy are some other secondary complications [101-104]. Regeneration and differentiation capability of stem cells make it possible to explore their therapeutic potential to treat and control diabetic complications. Specifically, the multipotent stem cells such as MSCs/HSCs, progenitor stem cells, tissue-specific stem cells, and pluripotent stem cells (ESCs and iPSCs) are considered to counter the diabetes-associated disorders $[98,100]$. Therefore, the selection of the suitable source of stem cells is critical to ensure the differentiation of stem cells into both endothelial and perivascular cells to repair diabetic complications [105]. In the further sections, we have discussed the role of stem cell therapy in several diabetic complications.

\section{Microvascular Diabetic Complication and Stem Cells}

7.1. Stem Cells and Diabetic Retinopathy. Abnormal ocular vascularity and retinal lesions lead to the development of blindness in retinopathy. The diabetic retinopathy (DR) is more prevalent in T1DM patients; however, it is hard to differentiate its incidence between T1DM and T2DM [106, 107]. DR is classed as either nonproliferative diabetic retinopathy (NPDR) or as proliferative diabetic retinopathy (PDR) [108]. Microvascular alterations cause retinal ischemia in NPDR, whereas PDR is caused by disruption of the ocular vitreous cavity due to the generation of abnormal blood cells leading to blindness $[106,109,110]$. Contemporary therapies such as vitrectomy and laser photocoagulation do not address the root cause of the disease [111]. Thus, stem cells seem as the most effective long-term treatment option for DR. In previous studies, MSCs and HSCs have been reported for their potential to differentiate into ocular cells to repair retinal damages [104]. In a seminal study in a rat model, it has been evidenced that MSCs are capable enough to mitigate and recover the loss of visual impairments $[112,113]$. Scalinci et al. found that neuroprotective growth factors such as brain-derived neurotrophic factor (BDNF), ciliary-derived neurotrophic factor (CTNF), nerve growth factor (NGF), glial-derived neurotrophic factor (GDNF), and basic fibroblast growth factor (bFGF) were significantly increased in DR rata injected with hMSCs [114]. However, inferior homing capacity of intravitreally administered MSCs and increased level of vascular endothelial growth factor (VEGF), a factor responsible for vascular lesion, were found. In another study, atorvastatin, a reductase inhibitor enzyme, had also reduced VEGF when MSCs were injected and hypoxic condition was maintained subsequently [115]. Siqueira et al. also demonstrated that BM-HSCs led to an improved visual activity [116]. Further, in animal models, the injected EPCs derived from murine BMSCs and hUCB promoted neovascularization and ameliorated DR [117-119].

7.2. Stem Cell in Diabetic Neuropathy. Diabetic neuropathy (DN) is one of the most prevalent complications among T1DM and T2DM patients, which may lead to foot ulcers and limb amputation [120]. DN becomes more chronic with an increase in the level of hyperglycemia and with the passage of time [121, 122]. Microvascular factors, metabolic regulations, unregulated glucose level, increased glycated hemoglobin level, oxidative and nitrosative stress, and reduced blood flow rate (due to the accumulation of ROS) are some factors which are attributed to the incidence of DN $[121,123]$. ROS and reactive nitrogen species reduce blood flow leading to microvascular ischemia, which finally disrupts the function of the nerve [124]. Prolonged hyperglycemia also promotes the production of AGEs which after binding to RAGEs trigger an inflammatory response and enhance oxidative stress, leading to degeneration of Schwann cells. These cells not only insulate neuron but also regulate nerve regeneration, and any oxidation-mediated loss in their function promotes DN among diabetic patients $[124,125]$.

To develop an efficient therapy against $\mathrm{DN}$, the treatment procedure should address both neurotrophic and angiogenic requirements simultaneously. Considering these requirements, stem cells seem viable and efficient, as they are capable to synthesize neurotrophic, angiogenic, and other essential factors required for regeneration of neuronal and vascular cells. The multilineage potential and adherent nature of MSCs cells helps it to secrete factors which are essential for 
neurotrophic and angiogenic effects. Different studies have revealed that MSCs improved DN symptoms in streptozotocin- (STZ-) induced diabetic rats. Though this treatment, VEGF and fibroblast growth factor-2 (FGF2) were increased and the capillary number to muscle fiber ratio in soleus muscles and sural nerve morphometry were improved [126]. In a multiple intravenous MSC treatment in STZinduced T2DM rats, a controlled hyperglycemia with enhanced serum insulin and C-peptide was found at 9 weeks [127]. Motor and sensory nerve function restored in BMSC-treated STZ-induced diabetic rat [128]. Nerve regeneration has also been demonstrated with combined treatment of human MSCs and poly (3-hydroxybutyrateco-3-hydroxyhexanoate) in Sprague-Dawley albino rats [129]. These animal-based studies strongly indicate that MSCs should have essential elements to address DN complications. However, lack of established clinical procedures, risk of tumor formation, and lack of understanding of clear mechanism are posing challenges to MSCs' candidacy as a therapeutic agent for DN [120].

7.3. Stem Cells in Diabetic Nephropathy. Diabetic nephropathy (DNP) is responsible for high mortality and a major contributor in end-stage chronic renal disease [130, 131]. Podocytes, the matrix molecule-synthesizing elements in the glomerular basement membrane, are injured and lost in DNP, leading to proteinuria and fibrosis and finally to renal failure. The regeneration capacities of podocytes are limited when injured, and it will adversely affect the glomerular barrier, further aggravating proteinuria [132]. Proteinuria promotes the dysfunction of proximal tubular epithelial cells (PTECs) by increasing fibrosis and tubulointerstitial inflammation, resulting in decreased renal activity [133]. Increase in immune cells in the interstitium is a characteristic feature of DNP [131]. Prolong hyperglycemia, AGEs, and glycated albumin enhance the inflammatory and fibrotic properties of PTECs [134]. AGEs also activate the reninangiotensin system (RAS), triggering the secretion of ROS thereby increasing the formation of cytokine and growth factors [135]. In an important study, an enhanced DNP symptom in mice was revealed through an increased level of carboxymethyl-lysine (CML) an advanced glycation end product [136]. However, the ESCs, under the presence of required growth factors, including retinoic acid, activin A, BMP-2, BMP-7, and FGF-7, can be differentiated into renal cells $[137,138]$. Various studies have also successfully differentiated iPSCs into renal cells to improvise the DNP characteristics $[139,140]$. MSCs have also been introduced into an STZ-induced diabetic rat to repair renal damage and regenerate insulin-secreting cells [141, 142], whereas the stromal cell-derived factor (SDF-1) promoted homing of MSCs when released in the kidneys [143]. Nagaishi et al. demonstrated that BM-MSCs inhibited the proinflammatory cytokine, TGF- $\beta 1$, and fibrosis in tubular interstitium They further revealed exosome-assisted antiapoptotic effect in tight junction structures of tubular interstitial cells indicating improved DNP [130]. The MSCs also exerted regenerative and protective effects in DNP by improvement in fibrosis and glomerulosclerosis, possibly via reducing the loss of podocytes and increased the secretion of BMP-7 [144]. BM-MSC treatment has regulated the serum level of insulin, hemeoxygenase-1, AGEs, and glucose with recovery in renal function [145]. Overall, the role of MSCs in the treatment of DNP is prospective, however, it is limited due to previously discussed hurdles.

\section{Stem Cells in Macrovascular and Other Complications}

DM patients are prone to atherosclerosis in large arteries finally developing macrovascular complication in the artery. Prolong hyperglycemia and atherosclerosis enhance the risk of myocardial infarction, artery disease, and stroke [98, 146]. CD 133 and CD34 are potent markers of cardiovascular diseases (CVD), and reduction in EPCs is used as an indicator of peripheral artery disease (PAD) [147-149]. Vascular stem cells (VSCs) are capable to differentiate EPCs and are a potential target for treatment of diabetic macrovascular complications. Vascular progenitor cell isolated from human vascular smooth muscle cells under proper condition was able to grow into vascular networks [150]. In a report, Keats and Khan proposed a hypothesis to develop vascular network from CD133+ VSC due to its ability to differentiate into EPCs and MPCs [105]. Further, the interaction between AGEs and RAGEs plays a critical role in the development of macroangiopathy and macrovascular complications [105].

8.1. Stem Cells in Diabetic Cardiomyopathy. Diabetic cardiomyopathy (DCM) is mainly developed due to cellular apoptosis. DCM reduces tissue-specific stem cells, intensifies fibrosis, and decreases perfusion in the capillaries [151,152]. This complication is characterized by the reduced activity of metalloproteases-2 (MMP-2), high collagen in specific tissue, and upregulated activity of apoptotic factor MMP-9 [98]. However, MSCs have also been implicated in regenerating myocardial cells for restoring normal function of the heart. Specifically, administration of BM-MSCs has shown to improve diabetic myocardium in the T1DM rat by reducing collagen level and activity of MMP-9 [153]. Other stem cells such as ESCs, iPSCs, and cardiac stem cells had also been explored to recover myocardial infarction in animal models [154-156].

Besides, MSCs also induce myogenesis and angiogenesis by releasing various angiogenic, mitogenic, and antiapoptotic factors, including vascular endothelial growth factor (VEGF), insulin-like growth factor-1 (IGF-1), adrenomedullin (AM), and hepatocyte growth factor (HGF) [20]. This was demonstrated using a rat model of DCM [20], wherein intravenously administered rat BM-MSCs improved cardiac function via differentiating into cardiomyocytes and improved myogenesis and angiogenesis. In addition, the activity of MMP-2 was significantly increased, while MMP9 increased, which led to enhanced myocardial arteriolar density and reduced collagen volume. MSCs also promoted the secretion of Bcl-2, hypoxia-related HOM-1, HSP-20, stromal cell-derived growth factor, and VEGF under hypoxic condition and stimulated neovascularization and restored myocardial function [157-159]. Notably, 
the site of injection and cell load has also been considered as determinants for improvement in myocardial infarction during MSC therapy [160].

8.2. Stem Cells in Diabetic Bone. T1DM and T2DM both interfere with normal osteogenic pathways, resulting in elevated risk of bone fractures and reduced ability of fracture healing. Bone-associated complications, affecting osteoblasts and osteoclasts, are mainly attributed to increased levels of AGEs, inflammation, and ROS [161]. AGEs not only block the osteoblastic differentiation and formation of mineralized matrix but also promote apoptosis of osteoblast, leading to impaired bone formation $[162,163]$. Interaction between blood vessels and bone cells promotes regeneration and repair of the bone, which is disrupted in a hyperglycemic microenvironment, thereby hindering the repair of bone fracture [164]. Increase in secretion of TNF- $\alpha$, IFN- $\gamma$-inducible protein 10 (IP-10), IL-1 $\beta$, IL-6, and high-sensitivity C-reactive protein (hsCRP) was also reported after bone fracture in T2DM patients [165]. Current grafting procedures for treatments are limited due to rejection, difficulty in integration, long-term relief, and cost [166]. To overcome these challenges, the tissue engineering approaches have been used in MSCs are considered as leading therapeutic candidates [164]. MSCs are capable to differentiate into osteoblasts and also secrete factors such as VEGF and BMP-4 to promote bone cell regeneration $[167,168]$. Studies have also used immortalized BMSCs in osteoarthritic recovery [169]. These studies showed the potential of MSC therapy in boneassociated disorders. However, further studies are still needed to establish a definite role of MSCs in the treatment of these disorders. Furthermore, the role of pluripotent and other adult stem cells in regeneration and repair of bone is also needed to be extensively explored.

8.3. Stem Cells in Wound Healing. Persistent and long-term hyperglycemia disrupts the wound healing capacity of T1DM and T2DM patients leading to chronic wound [170] and increases the risk of opportunistic infections. This chronic condition is developed due to impaired angiogenesis, uncontrolled release of growth factors, and incoherence in the accumulation of collagen matrix [98]. The increased rate of apoptosis of EPC and their numbers among DM patients have already been observed [171]. Additionally, the high level of inflammatory cytokines like TNF- $\alpha$, CRP, and IL- 8 are also found to be associated with poor wound healing capacity. Other factors related to collagen metabolism such as keratinocyte growth factor (KGF), transforming growth factor $\beta$ (TGF- $\beta$ ), epidermal growth factor (EGF), platelet-derived growth factor (PDGF), and VEGF are also associated with chronic diabetic wound [172]. However, studies have demonstrated that both the MSCs and EPCs were recruited at the injury site and exerted the healing effect [98]. In a study, the iPSCs showed wound healing in diabetic patients by increasing the level of proangiogenic factors and controlled the activity of protein kinase $\mathrm{C}$ delta $(\mathrm{PKC}-\delta)$ [173]. Another study demonstrated increased collagen accumulation in diabetic fascial wounds of rats, when treated with BM-MSCs which have been ascribed to the secretome of growth factors such as TGF- $\beta, \mathrm{KGF}$, EGF, PDGF, and VEGF, essential to healing efficacy [174]. These factors also improve cell adhesion and promote an increase in secretion of chemokines at wound site $[157,158]$. In various previous studies on animal models, MSC therapy has already been evidenced with an improved wound healing, for which different mechanisms have been explained [104, 174-177].

\section{Combinatorial and Coculture Approaches in Stem Cell-Based Therapy of Diabetes and Its Complications}

Therapeutic potency of stem cells is still in developmental phase for diabetic treatment, and the interactive effect of other chemical molecules on stem cell-based therapy is needed to be widely screened to improve their efficacy and safety. The pathological state such as diabetic wound healing have limited therapeutic options; however, a therapeutic combinational approach using ADSCs and exendin-4 (Ex-4) significantly improved the wound healing than singleton treatment in diabetic mice [178]. This effect was exhibited through proliferation and migration of endothelial cells and keratinocytes. Another combinatorial effect of MSCs and obestatin significantly improved the pancreatic damage in the T2DM rat model [179]. This was achieved through obestatin-mediated promotion of proliferation of active $\beta$ cells or islet-like cell clusters in vitro. Similarly, a study demonstrated the cumulative therapeutic effect of icariin and MSCs towards diabetes-induced erectile dysfunction, where icariin enhanced the therapeutic potential of ADSCs through its antioxidative and antiapoptotic activities [180]. In an interesting study, murine ESCs differentiated rapidly into pancreatic $\beta$-cells by using activin $\mathrm{A}$, all-trans retinoic acid and some other factors such as Matrigel [181]. These differentiated cells were able to control the blood glucose level in vivo in the diabetic murine model; however, tumor formation in the kidney limited the use of transplanted cells. Besides, the impaired endothelial progenitor cell (EPC) homing reduce the wound healing ability in the diabetic microenvironment, which is associated with reduced expression of stromal cell-derived factor- $1 \alpha$ (SDF- $1 \alpha)$. However, the homing of EPCs can be improved at wound site under hyperoxia and via administration of SDF- $1 \alpha$ [182]. In a clinical study, the synergistic administration of hyperbaric oxygen and intrapancreatic autologous stem cell was effective in controlling the metabolic level of insulin in T2DM patients [96]. It has also been shown that the preconditioning of the stem cell might improve the efficacy of cell-based therapy. MSCs harvested from diabetic mice were preconditioned in presence of insulin-like growth factor-1 (IGF-1) and fibroblast growth factor-2 (FGF-2) in medium and were further acclimatized under hypoxia and high glucose condition. After implantation of conditioned MSCs, the improvement in heart condition of diabetic mice was observed, indicating stem cell-based strategies to treat diabetic heart failure [183].

Recently, coculture techniques have also been used to improvise the efficacy of stem cells through enhancing their differentiation potential. In a study, the ESCs were cocultured 
with hepatocytes and induced to differentiate into endodermal cells, which were further induced to differentiate into pancreatic islet cells in presence of Matrigel and retinoid [184]. Another experimental study showed that differentiated islet cell clusters from human Wharton's jelly-derived mesenchymal stem cells in the presence of rat pancreatic cells could suppress blood glucose level [185]. Cotransplantation of kidney-derived MSCs with islets in diabetic mice has also remodelled islet organization and vascularization and reduced hyperglycemia [186]. Similarly, a seminal study pointed out that the viability of isolated islet was improved, when cocultured with collagen mixed hydrogel (collagen type I, collagen type III, and laminin) [187]. It is of note that the coculture system is used not only in improving therapeutic efficacy of stem cells but also to contemplate the pathogenesis of diabetes. In a conclusive study, a coculture system of BMSCs and macrophage helped to understand that association between local inflammation and immune response promotes diabetic periodontitis, particularly by upregulating the expression of chemokine (C-C motif) ligand 2 (CCL2) and TNF- $\alpha$ in periodontal tissues [188].

\section{Gene Editing in Stem Cell for Treatment of Diabetes and Its Complications}

Recent developments in gene targeting, editing, and delivery have made it feasible to develop an effective and long-term therapy for the treatment of genetic disorders. Adult stem cells, such as HSCs and MSCs are considered as promising candidates for exploiting gene modification techniques in cell-based regenerative therapy [189-191]. Vectors derived from retroviruses and adenoviruses are most commonly used to transfer the genes in stem cells; however, the chances of random integration might be deleterious. The other limiting factor associated with gene editing is no retaining of the edited gene by stem cells during their ex vivo proliferation. To overcome the limitations of viral vectors genetic control elements such as scaffold attachment region (SAR) and chicken beta-globin locus are added into the vectors to effectively control the gene expression in stem cells [192]. In diabetic mice, the transplanted BM-MSC expressing pancreatic duodenal homeobox $1(\mathrm{Pdx} 1)$ gene differentiated into insulin-releasing $\beta$-cell and controlled the glucose level [193]. Similarly, a seminal study showed that the transfected MSCs with vascular endothelial growth factor (VEGF) gene improved the erectile dysfunction in diabetic rats [194]. Though this stem cell-mediated gene therapy demonstrated successful results in rats, it possesses a few limitations as it was carried out only in the T1DM animal model and used adenovirus vector is not considered as a robust gene expression system. In a recent interesting study, the genetically modified human urine-derived stem cells with FGF2 gene significantly improved ED in T2DM SD-rat model [195].

Recent gene editing techniques such as zinc-finger nucleases (ZFNs), transcription activator-like effector nucleases (TALENs), and the clustered regularly interspaced short palindromic repeats-associated Cas protein system (CRISPR/Cas) seems promising to understand the role of specific genes in beta cell development and to manipulate the stem cell differentiation into insulin-producing cells [196]. The CRISPR/Cas9 system is currently favoured due to its modularity, flexibility, specificity, reduced toxicity, ease of designing target single-guide RNA (sgRNA) and reduced side effects. Gene-editing techniques have clearly established the role of transcription factor, neurogenin 3 in development of endocrine cells of pancreas, and demonstrated that even low expression of this factor is sufficient to promote the stem cell differentiation into insulin-producing beta cells [197]. Further, the CRISPR/Cas9 mediated deletion of CDKAL1, KCNJ11, and KCNQ1 genes in hESCs disrupted the regulated production of insulin in differentiated beta cells. These recent studies imply that human pluripotent stem cells can be exploited as an effective model to understand molecular development of insulin-producing pancreatic beta cells [196]. Furthermore, the clear understanding of genetic regulation will help in developing and controlling the differentiation of functional beta cells. Notably, gene editing in stem cells also help to escape immune response during transplantation of differentiated cells. This was evidenced in a study in which complete knock out of human leukocyte antigens (HLAs) class-I through disrupting beta 2-microglobulin $(\beta 2 \mathrm{~m})$ in hESCs maintained the cellular pluripotency level with significantly reduced immunogenicity [198].

\section{Conclusions}

The diabetic complications are the most prominent reason for high mortality among diabetic patients; therefore, due to proven repair and regeneration potential, the cell-based therapies, including pluripotent and multipotent adult stem cells are currently being considered. This therapeutic approach will not only be helpful to overcome the limitations of contemporary therapy but also provide a long-term cure for diabetes and its complications. However, extensive studies are needed to establish standard procedures for stem cell treatment in diabetic complications.

\section{Conflicts of Interest}

The authors declare that there is no conflict of interest regarding the publication of this paper.

\section{References}

[1] K. S. Polonsky, "The past 200 years in diabetes," The New England Journal of Medicine, vol. 367, no. 14, pp. 13321340, 2012.

[2] P. Zimmet, K. G. Alberti, D. J. Magliano, and P. H. Bennett, "Diabetes mellitus statistics on prevalence and mortality: facts and fallacies," Nature Reviews Endocrinology, vol. 12, no. 10, pp. 616-622, 2016

[3] American Diabetes Association, "Diagnosis and classification of diabetes mellitus," Diabetes Care, vol. 37, Supplement 1, pp. S81-S90, 2014.

[4] T. K. Bratanova-Tochkova, H. Cheng, S. Daniel et al., "Triggering and augmentation mechanisms, granule pools, and biphasic insulin secretion," Diabetes, vol. 51, Supplement 1, pp. S83-S90, 2002. 
[5] M. Raffaele, G. Li Volti, I. A. Barbagallo, and L. Vanella, "Therapeutic efficacy of stem cells transplantation in diabetes: role of Heme oxygenase," Frontiers in Cell and Developmental Biology, vol. 4, 2016.

[6] H. Vlassara and J. Uribarri, "Advanced glycation end products (AGE) and diabetes: cause, effect, or both?," Current Diabetes Reports, vol. 14, no. 1, p. 453, 2014.

[7] E. L. M. Guimaraes, C. Empsen, A. Geerts, and L. A. van Grunsven, "Advanced glycation end products induce production of reactive oxygen species via the activation of NADPH oxidase in murine hepatic stellate cells," Journal of Hepatology, vol. 52, no. 3, pp. 389-397, 2010.

[8] M. Zhang, A. L. Kho, N. Anilkumar et al., "Glycated proteins stimulate reactive oxygen species production in cardiac myocytes: involvement of Nox2 (gp91phox)-containing NADPH oxidase," Circulation, vol. 113, no. 9, pp. 1235-1243, 2006.

[9] A. Bierhaus, S. Schiekofer, M. Schwaninger et al., "Diabetesassociated sustained activation of the transcription factor nuclear factor- $\kappa$ B," Diabetes, vol. 50, no. 12, pp. 2792-2808, 2001.

[10] K. C. B. Tan, S. W. M. Shiu, Y. Wong, and X. Tam, "Serum advanced glycation end products (AGEs) are associated with insulin resistance," Diabetes/Metabolism Research and Reviews, vol. 27, no. 5, pp. 488-492, 2011.

[11] G. Marrazzo, I. Barbagallo, F. Galvano et al., "Role of dietary and endogenous antioxidants in diabetes," Critical Reviews in Food Science and Nutrition, vol. 54, no. 12, pp. 1599-1616, 2014.

[12] M. A. Lilly, M. F. Davis, J. E. Fabie, E. B. Terhune, and G. I. Gallicano, "Current stem cell based therapies in diabetes," American Journal of Stem Cells, vol. 5, no. 3, pp. 87-98, 2016.

[13] B. H. Fryer, A. Rezania, and M. C. Zimmerman, "Generating $\beta$-cells in vitro: progress towards a holy grail," Current Opinion in Endocrinology, Diabetes, and Obesity, vol. 20, no. 2, pp. 112-117, 2013.

[14] L. Bouwens, I. Houbracken, and J. K. Mfopou, "The use of stem cells for pancreatic regeneration in diabetes mellitus," Nature Reviews Endocrinology, vol. 9, no. 10, pp. 598-606, 2013.

[15] J. K. Biehl and B. Russell, "Introduction to stem cell therapy," Journal of Cardiovascular Nursing, vol. 24, no. 2, pp. 98-103, 2009.

[16] T. J. Nelson, A. Behfar, S. Yamada, A. Martinez-Fernandez, and A. Terzic, "Stem cell platforms for regenerative medicine," Clinical and Translational Science, vol. 2, no. 3, pp. 222-227, 2009.

[17] M. D. McCall, C. Toso, E. E. Baetge, and A. M. J. Shapiro, "Are stem cells a cure for diabetes?," Clinical Science, vol. 118, no. 2, pp. 87-97, 2009.

[18] B. Soria, F. J. Bedoya, J. R. Tejedo et al., "Cell therapy for diabetes mellitus: an opportunity for stem cells?," Cells, Tissues, Organs, vol. 188, no. 1-2, pp. 70-77, 2008.

[19] S. Sheik Abdulazeez, "Diabetes treatment: a rapid review of the current and future scope of stem cell research," Saudi Pharmaceutical Journal, vol. 23, no. 4, pp. 333-340, 2015.

[20] S. Kourembanas, "Exosomes: vehicles of intercellular signaling, biomarkers, and vectors of cell therapy," Annual Review of Physiology, vol. 77, no. 1, pp. 13-27, 2015.

[21] M. Nawaz, F. Fatima, K. C. Vallabhaneni et al., "Extracellular vesicles: evolving factors in stem cell biology," Stem Cells International, vol. 2016, no. 17, 17 pages, 2016.
[22] G. S. L. Teo, J. A. Ankrum, R. Martinelli et al., "Mesenchymal stem cells transmigrate between and directly through tumor necrosis factor- $\alpha$-activated endothelial cells via both leukocyte-like and novel mechanisms," Stem Cells, vol. 30, no. 11, pp. 2472-2486, 2012.

[23] S. Aggarwal and M. F. Pittenger, "Human mesenchymal stem cells modulate allogeneic immune cell responses," Blood, vol. 105, no. 4, pp. 1815-1822, 2005.

[24] M. Di Nicola, C. Carlo-Stella, M. Magni et al., "Human bone marrow stromal cells suppress T-lymphocyte proliferation induced by cellular or nonspecific mitogenic stimuli," Blood, vol. 99, no. 10, pp. 3838-3843, 2002.

[25] L. Raffaghello, G. Bianchi, M. Bertolotto et al., "Human mesenchymal stem cells inhibit neutrophil apoptosis: a model for neutrophil preservation in the bone marrow niche," Stem Cells, vol. 26, no. 1, pp. 151-162, 2008.

[26] B. Bussolati, "Stem cells for organ repair: support or replace?," Organogenesis, vol. 7, no. 2, p. 95, 2011.

[27] M. Li and S. Ikehara, "Bone-marrow-derived mesenchymal stem cells for organ repair," Stem Cells International, vol. 2013, Article ID 132642, 8 pages, 2013.

[28] Y. Xiao, X. Li, H. Hao et al., "Secretome of mesenchymal stem cells," in Essentials of Mesenchymal Stem Cell Biology and Its Clinical Translation, pp. 33-46, Springer, Dordrecht, 2013.

[29] L. Beer, M. Mildner, and H. J. Ankersmit, "Cell secretome based drug substances in regenerative medicine: when regulatory affairs meet basic science," Annals of Translational Medicine, vol. 5, no. 7, p. 170, 2017.

[30] R. Z. Murray and J. L. Stow, "Cytokine secretion in macrophages: SNAREs, Rabs, and membrane trafficking," Frontiers in Immunology, vol. 5, 2014.

[31] N. Chaput and C. Thery, "Exosomes: immune properties and potential clinical implementations," Seminars in Immunopathology, vol. 33, no. 5, pp. 419-440, 2011.

[32] J. Ratajczak, M. Wysoczynski, F. Hayek, A. JanowskaWieczorek, and M. Z. Ratajczak, "Membrane-derived microvesicles: important and underappreciated mediators of cell-to-cell communication," Leukemia, vol. 20, no. 9, pp. 1487-1495, 2006.

[33] G. Camussi, M. C. Deregibus, S. Bruno, V. Cantaluppi, and L. Biancone, "Exosomes/microvesicles as a mechanism of cell-to-cell communication," Kidney International, vol. 78, no. 9, pp. 838-848, 2010.

[34] H. Valadi, K. Ekström, A. Bossios, M. Sjöstrand, J. J. Lee, and J. O. Lötvall, "Exosome-mediated transfer of mRNAs and microRNAs is a novel mechanism of genetic exchange between cells," Nature Cell Biology, vol. 9, no. 6, pp. 654659, 2007.

[35] B. György, T. G. Szabó, M. Pásztói et al., "Membrane vesicles, current state-of-the-art: emerging role of extracellular vesicles," Cellular and Molecular Life Sciences, vol. 68, no. 16, pp. 2667-2688, 2011.

[36] B. Yu, X. Zhang, and X. Li, "Exosomes derived from mesenchymal stem cells," International Journal of Molecular Sciences, vol. 15, no. 3, pp. 4142-4157, 2014.

[37] M. Zöller, "Tetraspanins: push and pull in suppressing and promoting metastasis," Nature Reviews Cancer, vol. 9, no. 1, pp. 40-55, 2009.

[38] C. Théry, M. Ostrowski, and E. Segura, "Membrane vesicles as conveyors of immune responses," Nature Reviews Immunology, vol. 9, no. 8, pp. 581-593, 2009. 
[39] M. Hristov, W. Erl, S. Linder, and P. C. Weber, "Apoptotic bodies from endothelial cells enhance the number and initiate the differentiation of human endothelial progenitor cells in vitro," Blood, vol. 104, no. 9, pp. 2761-2766, 2004.

[40] M. Gnecchi, H. He, N. Noiseux et al., "Evidence supporting paracrine hypothesis for Akt-modified mesenchymal stem cell-mediated cardiac protection and functional improvement," The FASEB Journal, vol. 20, no. 6, pp. 661-669, 2006.

[41] M. Wang, W. Zhang, P. Crisostomo et al., "STAT3 mediates bone marrow mesenchymal stem cell VEGF production," Journal of Molecular and Cellular Cardiology, vol. 42, no. 6, pp. 1009-1015, 2007.

[42] Z. Liu, M. Lei, Y. Jiang et al., "High glucose attenuates VEGF expression in rat multipotent adult progenitor cells in association with inhibition of JAK2/STAT3 signalling," Journal of Cellular and Molecular Medicine, vol. 13, no. 9b, pp. 3427-3436, 2009.

[43] Y. Wang, P. R. Crisostomo, M. Wang, T. A. Markel, N. M. Novotny, and D. R. Meldrum, "TGF- $\alpha$ increases human mesenchymal stem cell-secreted VEGF by MEK- and PI3-K- but not JNK- or ERK-dependent mechanisms," American Journal of Physiology - Regulatory, Integrative and Comparative Physiology, vol. 295, no. 4, pp. R1115-R1123, 2008.

[44] T. A. Markel, P. R. Crisostomo, M. Wang, C. M. Herring, and D. R. Meldrum, "Activation of individual tumor necrosis factor receptors differentially affects stem cell growth factor and cytokine production," American Journal of Physiology Gastrointestinal and Liver Physiology, vol. 293, no. 4, pp. G657-G662, 2007.

[45] Y. Wang, B. R. Weil, J. L. Herrmann et al., "MEK, p38, and PI-3K mediate cross talk between EGFR and TNFR in enhancing hepatocyte growth factor production from human mesenchymal stem cells," American Journal of Physiology-Cell Physiology, vol. 297, no. 5, pp. C1284C1293, 2009.

[46] B.-K. Nguyen, S. Maltais, L. P. Perrault et al., "Improved function and myocardial repair of infarcted heart by intracoronary injection of mesenchymal stem cell-derived growth factors," Journal of Cardiovascular Translational Research, vol. 3, no. 5, pp. 547-558, 2010.

[47] T. A. Markel, M. Wang, P. R. Crisostomo, M. C. Manukyan, J. A. Poynter, and D. R. Meldrum, "Neonatal stem cells exhibit specific characteristics in function, proliferation, and cellular signaling that distinguish them from their adult counterparts," American Journal of Physiology-Regulatory, Integrative and Comparative Physiology, vol. 294, no. 5, pp. R1491-R1497, 2008.

[48] M. C. Manukyan, B. R. Weil, Y. Wang et al., "Female stem cells are superior to males in preserving myocardial function following endotoxemia," American Journal of Physiology-Regulatory, Integrative and Comparative Physiology, vol. 300, no. 6, pp. R1506-R1514, 2011.

[49] P. R. Crisostomo, M. Wang, C. M. Herring et al., "Gender differences in injury induced mesenchymal stem cell apoptosis and VEGF, TNF, IL- 6 expression: role of the $55 \mathrm{kDa}$ TNF receptor (TNFR1)," Journal of Molecular and Cellular Cardiology, vol. 42, no. 1, pp. 142-149, 2007.

[50] C. Heeschen, R. Lehmann, J. Honold et al., "Profoundly reduced neovascularization capacity of bone marrow mononuclear cells derived from patients with chronic ischemic heart disease," Circulation, vol. 109, no. 13, pp. 16151622, 2004.
[51] N. Krankel, V. Adams, A. Linke et al., "Hyperglycemia reduces survival and impairs function of circulating bloodderived progenitor cells," Arteriosclerosis, Thrombosis, and Vascular Biology, vol. 25, no. 4, pp. 698-703, 2005.

[52] R. O. Hynes, "Integrins: versatility, modulation, and signaling in cell adhesion," Cell, vol. 69, no. 1, pp. 11-25, 1992.

[53] E. C. Lai, "Notch signaling: control of cell communication and cell fate," Development, vol. 131, no. 5, pp. 965-973, 2004.

[54] P. C. Schiller, G. D'Ippolito, R. Brambilla, B. A. Roos, and G. A. Howard, "Inhibition of gap-junctional communication induces the trans-differentiation of osteoblasts to an adipocytic phenotype in vitro," Journal of Biological Chemistry, vol. 276, no. 17, pp. 14133-14138, 2001.

[55] J. E. Trosko, "The role of stem cells and gap junctional intercellular communication in carcinogenesis," BMB Reports, vol. 36, no. 1, pp. 43-48, 2003.

[56] M. Xu, M. Wani, Y. S. Dai et al., "Differentiation of bone marrow stromal cells into the cardiac phenotype requires intercellular communication with myocytes," Circulation, vol. 110, no. 17, pp. 2658-2665, 2004.

[57] A. Rustom, R. Saffrich, I. Markovic, P. Walther, and H.H. Gerdes, "Nanotubular highways for intercellular organelle transport," Science, vol. 303, no. 5660, pp. 1007-1010, 2004.

[58] L. Marzo, K. Gousset, and C. Zurzolo, "Multifaceted roles of tunneling nanotubes in intercellular communication," Frontiers in Physiology, vol. 3, 2012.

[59] H.-H. Gerdes, A. Rustom, and X. Wang, "Tunneling nanotubes, an emerging intercellular communication route in development," Mechanisms of Development, vol. 130, no. 68, pp. 381-387, 2013.

[60] M. Li and S. Ikehara, "Stem cell treatment for type 1 diabetes," Frontiers in Cell and Developmental Biology, vol. 2, 2014.

[61] L. Li, M. L. Baroja, A. Majumdar et al., "Human embryonic stem cells possess immune-privileged properties," Stem Cells, vol. 22, no. 4, pp. 448-456, 2004.

[62] M. Drukker, H. Katchman, G. Katz et al., "Human embryonic stem cells and their differentiated derivatives are less susceptible to immune rejection than adult cells," Stem Cells, vol. 24, no. 2, pp. 221-229, 2006.

[63] K. Mohib, D. Allan, and L. Wang, "Human embryonic stem cell-extracts inhibit the differentiation and function of monocyte-derived dendritic cells," Stem Cell Reviews and Reports, vol. 6, no. 4, pp. 611-621, 2010.

[64] A. Nasef, N. Ashammakhi, and L. Fouillard, "Immunomodulatory effect of mesenchymal stromal cells: possible mechanisms," Regenerative Medicine, vol. 3, no. 4, pp. 531-546, 2008.

[65] G. Chamberlain, J. Fox, B. Ashton, and J. Middleton, "Concise review: mesenchymal stem cells: their phenotype, differentiation capacity, immunological features, and potential for homing," Stem Cells, vol. 25, no. 11, pp. 2739-2749, 2007.

[66] A. Uccelli, L. Moretta, and V. Pistoia, "Mesenchymal stem cells in health and disease," Nature Reviews Immunology, vol. 8, no. 9, pp. 726-736, 2008.

[67] N. Nakatsuji, F. Nakajima, and K. Tokunaga, "HLA-haplotype banking and iPS cells," Nature Biotechnology, vol. 26, no. 7, pp. 739-740, 2008.

[68] A. Torsvik, G. V. Rosland, A. Svendsen et al., "Spontaneous malignant transformation of human mesenchymal stem cells reflects cross-contamination: putting the research field on 
track-letter," Cancer Research, vol. 70, no. 15, pp. 6393-6396, 2010.

[69] K. J. Godfrey, B. Mathew, J. C. Bulman, O. Shah, S. Clement, and G. I. Gallicano, "Stem cell-based treatments for type 1 diabetes mellitus: bone marrow, embryonic, hepatic, pancreatic and induced pluripotent stem cells," Diabetic Medicine, vol. 29, no. 1, pp. 14-23, 2012.

[70] P. Chhabra and K. L. Brayman, "Stem cell therapy to cure type 1 diabetes: from hype to hope," Stem Cells Translational Medicine, vol. 2, no. 5, pp. 328-336, 2013.

[71] R. T. Wagner, J. Lewis, A. Cooney, and L. Chan, "Stem cell approaches for the treatment of type 1 diabetes mellitus," Translational Research, vol. 156, no. 3, pp. 169-179, 2010.

[72] M. A. Hussain and N. D. Theise, "Stem-cell therapy for diabetes mellitus," The Lancet, vol. 364, no. 9429, pp. 203-205, 2004.

[73] Y. Hori, I. C. Rulifson, B. C. Tsai, J. J. Heit, J. D. Cahoy, and S. K. Kim, "Growth inhibitors promote differentiation of insulin-producing tissue from embryonic stem cells," Proceeding of the National Academy of Sciences of the United States of America, vol. 99, no. 25, pp. 16105-16110, 2002.

[74] P. Blyszczuk, J. Czyz, G. Kania et al., "Expression of Pax4 in embryonic stem cells promotes differentiation of nestinpositive progenitor and insulin-producing cells," Proceedings of the National Academy Sciences of the United States of America, vol. 100, no. 3, pp. 998-1003, 2003.

[75] S. Miyazaki, E. Yamato, and J. Miyazaki, "Regulated expression of pdx-1 promotes in vitro differentiation of insulin-producing cells from embryonic stem cells," Diabetes, vol. 53, no. 4, pp. 1030-1037, 2004.

[76] E. Kroon, L. A. Martinson, K. Kadoya et al., "Pancreatic endoderm derived from human embryonic stem cells generates glucose-responsive insulin-secreting cells in vivo," Nature Biotechnology, vol. 26, no. 4, pp. 443-452, 2008.

[77] K. Takahashi, K. Tanabe, M. Ohnuki et al., "Induction of pluripotent stem cells from adult human fibroblasts by defined factors," Cell, vol. 131, no. 5, pp. 861-872, 2007.

[78] K. Takahashi and S. Yamanaka, "Induction of pluripotent stem cells from mouse embryonic and adult fibroblast cultures by defined factors," Cell, vol. 126, no. 4, pp. 663-676, 2006.

[79] S. Miyazaki, H. Yamamoto, N. Miyoshi et al., "Emerging methods for preparing iPS cells," Japanese Journal of Clinical Oncology, vol. 42, no. 9, pp. 773-9, 2012.

[80] J. B. Kim, H. Zaehres, G. Wu et al., "Pluripotent stem cells induced from adult neural stem cells by reprogramming with two factors," Nature, vol. 454, no. 7204, pp. 646-650, 2008.

[81] Z. Alipio, W. Liao, E. J. Roemer et al., "Reversal of hyperglycemia in diabetic mouse models using induced-pluripotent stem (iPS)-derived pancreatic $\beta$-like cells," Proceedings of the National Academy of Sciences of the United States of America, vol. 107, no. 30, pp. 13426-13431, 2010.

[82] L.-Z. Cao, D.-Q. Tang, M. E. Horb, S.-W. Li, and L.-J. Yang, "High glucose is necessary for complete maturation of Pdx1-VP16 -expressing hepatic cells into functional insulin-producing cells," Diabetes, vol. 53, no. 12, pp. 31683178, 2004.

[83] K. Fujimoto and K. S. Polonsky, "Pdx1 and other factors that regulate pancreatic $\beta$-cell survival," Diabetes, Obesity \& Metabolism, vol. 11, Supplement 4, pp. 30-37, 2009.
[84] M. Zalzman, S. Gupta, R. K. Giri et al., "Reversal of hyperglycemia in mice by using human expandable insulin-producing cells differentiated from fetal liver progenitor cells," Proceedings of the National Academy of Sciences of the United States of America, vol. 100, no. 12, pp. 7253-7258, 2003.

[85] L. T.-T. Dang, N. K. Phan, and K. D. Truong, "Mesenchymal stem cells for diabetes mellitus treatment: new advances," Biomedical Research and Therapy, vol. 4, no. 1, p. 1062, 2017.

[86] G. I. Bell, H. C. Broughton, K. D. Levac, D. A. Allan, A. Xenocostas, and D. A. Hess, "Transplanted human bone marrow progenitor subtypes stimulate endogenous islet regeneration and revascularization," Stem Cells and Development, vol. 21, no. 1, pp. 97-109, 2012.

[87] N. E. Davis, D. Hamilton, and M. J. Fontaine, "Harnessing the immunomodulatory and tissue repair properties of mesenchymal stem cells to restore $\beta$ cell function," Current Diabetes Reports, vol. 12, no. 5, pp. 612-622, 2012.

[88] N. El Haddad, D. Heathcote, R. Moore et al., "Mesenchymal stem cells express serine protease inhibitor to evade the host immune response," Blood, vol. 117, no. 4, pp. 11761183, 2011.

[89] H. Mizuno, M. Tobita, and A. C. Uysal, "Concise review: adipose-derived stem cells as a novel tool for future regenerative medicine," Stem Cells, vol. 30, no. 5, pp. 804-810, 2012.

[90] V. Chandra, S. G, S. Muthyala et al., "Islet-like cell aggregates generated from human adipose tissue derived stem cells ameliorate experimental diabetes in mice," PLoS One, vol. 6, no. 6, article e20615, 2011.

[91] V. Chandra, S. G, S. Phadnis, P. D. Nair, and R. R. Bhonde, "Generation of pancreatic hormone-expressing islet-like cell aggregates from murine adipose tissue-derived stem cells," Stem Cells, vol. 27, no. 8, pp. 1941-1953, 2009.

[92] L. Zang, H. Hao, J. Liu, Y. Li, W. Han, and Y. Mu, "Mesenchymal stem cell therapy in type 2 diabetes mellitus," Diabetology \& Metabolic Syndrome, vol. 9, no. 1, p. 36, 2017.

[93] S. E. Inzucchi, "Oral antihyperglycemic therapy for type 2 diabetes: scientific review," JAMA, vol. 287, no. 3, pp. 360372, 2002.

[94] F. W. Pagliuca, J. R. Millman, M. Gürtler et al., "Generation of functional human pancreatic $\beta$ cells in vitro," Cell, vol. 159, no. 2, pp. 428-439, 2014.

[95] J. C. Voltarelli, C. E. B. Couri, M. C. Oliveira et al., "Stem cell therapy for diabetes mellitus," Kidney International Supplements, vol. 1, no. 3, pp. 94-98, 2011.

[96] E. J. Estrada, F. Valacchi, E. Nicora et al., "Combined treatment of intrapancreatic autologous bone marrow stem cells and hyperbaric oxygen in type 2 diabetes mellitus," Cell Transplantation, vol. 17, no. 12, pp. 1295-1304, 2008.

[97] A. Bhansali, V. Upreti, N. Khandelwal et al., "Efficacy of autologous bone marrow-derived stem cell transplantation in patients with type 2 diabetes mellitus," Stem Cells and Development, vol. 18, no. 10, pp. 1407-1416, 2009.

[98] S. Bernardi, G. M. Severini, G. Zauli, and P. Secchiero, "Cellbased therapies for diabetic complications," Experimental Diabetes Research, vol. 2012, Article ID 872504, 10 pages, 2012.

[99] K. Papatheodorou, N. Papanas, M. Banach, D. Papazoglou, and M. Edmonds, "Complications of diabetes 2016," Journal of Diabetes Research, vol. 2016, Article ID 6989453, 3 pages, 2016. 
[100] M. Khamaisi and S. E. Balanson, "Stem cells for diabetes complications: a future potential cure," Rambam Maimonides Medical Journal, vol. 8, no. 1, article e0008, 2017.

[101] J. M. Forbes and M. E. Cooper, "Mechanisms of diabetic complications," Physiological Reviews, vol. 93, no. 1, pp. 137-188, 2013.

[102] V. Falanga, "Wound healing and its impairment in the diabetic foot," The Lancet, vol. 366, no. 9498, pp. 1736-1743, 2005.

[103] O. Asghar, A. al-Sunni, K. Khavandi et al., "Diabetic cardiomyopathy," Clinical Science, vol. 116, no. 10, pp. 741-760, 2009.

[104] G. C. Davey, S. B. Patil, A. O’Loughlin, and T. O’Brien, "Mesenchymal stem cell-based treatment for microvascular and secondary complications of diabetes mellitus," Frontiers in Endocrinology, vol. 5, no. 86, 2014.

[105] E. C. Keats and Z. A. Khan, "Vascular stem cells in diabetic complications: evidence for a role in the pathogenesis and the therapeutic promise," Cardiovascular Diabetology, vol. 11, no. 1, p. 37, 2012.

[106] R. N. Frank, "Diabetic retinopathy," The New England Journal of Medicine, vol. 350, no. 1, pp. 48-58, 2004.

[107] J. H. Kempen, B. J. O'Colmain, M. C. Leske et al., "The prevalence of diabetic retinopathy among adults in the United States," Archives of Ophthalmology, vol. 122, no. 4, pp. 552563, 2004.

[108] N. A. Calcutt, M. E. Cooper, T. S. Kern, and A. M. Schmidt, "Therapies for hyperglycaemia-induced diabetic complications: from animal models to clinical trials," Nature Reviews Drug Discovery, vol. 8, no. 5, pp. 417-430, 2009.

[109] I. G. Lee, S. L. Chae, and J. C. Kim, "Involvement of circulating endothelial progenitor cells and vasculogenic factors in the pathogenesis of diabetic retinopathy," Eye, vol. 20, no. 5, pp. 546-552, 2006.

[110] S. Brunner, G.-H. Schernthaner, M. Satler et al., "Correlation of different circulating endothelial progenitor cells to stages of diabetic retinopathy: first in vivo data," Investigative ophthalmology \& visual science, vol. 50, no. 1, pp. 392-398, 2009.

[111] T. A. Ciulla, A. G. Amador, and B. Zinman, "Diabetic retinopathy and diabetic macular edema: pathophysiology, screening, and novel therapies," Diabetes Care, vol. 26, no. 9, pp. 2653-2664, 2003.

[112] S. Wang, B. Lu, S. Girman et al., "Non-invasive stem cell therapy in a rat model for retinal degeneration and vascular pathology," PLoS One, vol. 5, no. 2, article e9200, 2010.

[113] Y. Inoue, A. Iriyama, S. Ueno et al., "Subretinal transplantation of bone marrow mesenchymal stem cells delays retinal degeneration in the RCS rat model of retinal degeneration," Experimental Eye Research, vol. 85, no. 2, pp. 234-241, 2007.

[114] S. Z. Scalinci, S. Z. Scalinci, L. Scorolli et al., "Potential role of intravitreal human placental stem cell implants in inhibiting progression of diabetic retinopathy in type 2 diabetes: neuroprotective growth factors in the vitreous," Clinical Ophthalmology, vol. 5, pp. 691-696, 2011.

[115] S. Mottaghi, B. Larijani, and A. M. Sharifi, "Atorvastatin: an efficient step forward in mesenchymal stem cell therapy of diabetic retinopathy," Cytotherapy, vol. 15, no. 3, pp. 263266, 2013.

[116] R. C. Siqueira, A. Messias, V. P. Gurgel, B. P. Simões, I. U. Scott, and R. Jorge, "Improvement of ischaemic macular oedema after intravitreal injection of autologous bone marrow-derived haematopoietic stem cells," Acta Ophthalmologica, vol. 93, no. 2, pp. e174-e176, 2015.

[117] M. B. Grant, W. S. May, S. Caballero et al., "Adult hematopoietic stem cells provide functional hemangioblast activity during retinal neovascularization," Nature Medicine, vol. 8, no. 6, pp. 607-612, 2002.

[118] Y. P. R. Jarajapu and M. B. Grant, "The promise of cell based therapies for diabetic complications: challenges and solutions," Circulation Research, vol. 106, no. 5, pp. 854-869, 2010.

[119] M. R. Ritter, E. Banin, S. K. Moreno, E. Aguilar, M. I. Dorrell, and M. Friedlander, "Myeloid progenitors differentiate into microglia and promote vascular repair in a model of ischemic retinopathy," Journal of Clinical Investigation, vol. 116, no. 12, pp. 3266-3276, 2006.

[120] J. Y. Zhou, Z. Zhang, and G. S. Qian, "Mesenchymal stem cells to treat diabetic neuropathy: a long and strenuous way from bench to the clinic," Cell Death Discovery, vol. 2, no. 1, article 16055, 2016.

[121] J. W. Han, M. Y. Sin, and Y.-S. Yoon, "Cell therapy for diabetic neuropathy using adult stem or progenitor cells," Diabetes \& Metabolism Journal, vol. 37, no. 2, pp. 91-105, 2013.

[122] A. Verrotti, G. Loiacono, A. Mohn, and F. Chiarelli, "New insights in diabetic autonomic neuropathy in children and adolescents," European Journal of Endocrinology, vol. 161, no. 6, pp. 811-818, 2009.

[123] S. Lupachyk, H. Shevalye, Y. Maksimchyk, V. R. Drel, and I. G. Obrosova, "PARP inhibition alleviates diabetesinduced systemic oxidative stress and neural tissue 4hydroxynonenal adduct accumulation: correlation with peripheral nerve function," Free Radical Biology \& Medicine, vol. 50, no. 10, pp. 1400-1409, 2011.

[124] N. E. Cameron and M. A. Cotter, "Effects of antioxidants on nerve and vascular dysfunction in experimental diabetes," Diabetes Research and Clinical Practice, vol. 45, no. 2-3, pp. 137-146, 1999.

[125] K. Sugimoto, M. Yasujima, and S. Yagihashi, "Role of advanced glycation end products in diabetic neuropathy," Current Pharmaceutical Design, vol. 14, no. 10, pp. 953961, 2008.

[126] T. Shibata, K. Naruse, H. Kamiya et al., "Transplantation of bone marrow-derived mesenchymal stem cells improves diabetic polyneuropathy in rats," Diabetes, vol. 57, no. 11, pp. 3099-3107, 2008.

[127] H. Hao, J. Liu, J. Shen et al., "Multiple intravenous infusions of bone marrow mesenchymal stem cells reverse hyperglycemia in experimental type 2 diabetes rats," Biochemical and Biophysical Research Communications, vol. 436, no. 3, pp. 418-423, 2013.

[128] J. W. Han, D. Choi, M. Y. Lee, Y. H. Huh, and Y.-S. Yoon, "Bone marrow-derived mesenchymal stem cells improve diabetic neuropathy by direct modulation of both angiogenesis and myelination in peripheral nerves," Cell Transplantation, vol. 25, no. 2, pp. 313-326, 2016.

[129] M. Sakar, P. Korkusuz, M. Demirbilek et al., "The effect of poly(3-hydroxybutyrate-co-3- hydroxyhexanoate) (PHBHHx) and human mesenchymal stem cell (hMSC) on axonal regeneration in experimental sciatic nerve damage," International Journal of Neuroscience., vol. 124, no. 9, pp. 685-696, 2014.

[130] K. Nagaishi, Y. Mizue, T. Chikenji et al., "Mesenchymal stem cell therapy ameliorates diabetic nephropathy via the 
paracrine effect of renal trophic factors including exosomes," Scientific Reports, vol. 6, no. 1, article 34842, 2016.

[131] Y. Liu and S. C. W. Tang, "Recent progress in stem cell therapy for diabetic nephropathy," Kidney Diseases, vol. 2, no. 1, pp. 20-27, 2016.

[132] P. W. Mathieson, "The podocyte as a target for therapies-new and old," Nature Reviews Nephrology, vol. 8, no. 1, pp. 52-56, 2012.

[133] R. E. Gilbert and M. E. Cooper, "The tubulointerstitium in progressive diabetic kidney disease: more than an aftermath of glomerular injury?," Kidney International, vol. 56, no. 5, pp. 1627-1637, 1999.

[134] I. Grgic, G. Campanholle, V. Bijol et al., "Targeted proximal tubule injury triggers interstitial fibrosis and glomerulosclerosis," Kidney International, vol. 82, no. 2, pp. 172-183, 2012.

[135] K. Fukami, S. Yamagishi, S. Ueda, and S. Okuda, "Role of AGEs in diabetic nephropathy," Current Pharmaceutical Design, vol. 14, no. 10, pp. 946-952, 2008.

[136] S.-H. Yu, N. K. Dubey, W.-S. Li et al., "Cordyceps militaris treatment preserves renal function in type 2 diabetic nephropathy mice," PLoS One, vol. 11, no. 11, article e0166342, 2016.

[137] D. Kim and G. R. Dressler, "Nephrogenic factors promote differentiation of mouse embryonic stem cells into renal epithelia," Journal of the American Society of Nephrology, vol. 16, no. 12, pp. 3527-3534, 2005.

[138] K. Narayanan, K. M. Schumacher, F. Tasnim et al., "Human embryonic stem cells differentiate into functional renal proximal tubular-like cells," Kidney International, vol. 83, no. 4, pp. 593-603, 2013.

[139] B. Song, A. M. Smink, C. V. Jones et al., "The directed differentiation of human iPS cells into kidney podocytes," PLoS One, vol. 7, no. 9, article e46453, 2012.

[140] A. Q. Lam, B. S. Freedman, R. Morizane, P. H. Lerou, M. T. Valerius, and J. V. Bonventre, "Rapid and efficient differentiation of human pluripotent stem cells into intermediate mesoderm that forms tubules expressing kidney proximal tubular markers," Journal of the American Society of Nephrology, vol. 25, no. 6, pp. 1211-1225, 2014.

[141] M. E. Ezquer, F. E. Ezquer, M. L. Arango-Rodriguez, and P. A. Conget, "MSC transplantation: a promising therapeutic strategy to manage the onset and progression of diabetic nephropathy," Biological Research, vol. 45, no. 3, pp. 289296, 2012.

[142] F. E. Ezquer, M. E. Ezquer, D. B. Parrau, D. Carpio, A. J. Yanez, and P. A. Conget, "Systemic administration of multipotent mesenchymal stromal cells reverts hyperglycemia and prevents nephropathy in type 1 diabetic mice," Biology of Blood and Marrow Transplantation, vol. 14, no. 6, pp. 631640, 2008.

[143] Y. Gao, S. Wu, L. Li et al., "Ultrasound-targeted stromal cellderived factor-1-loaded microbubble destruction promotes mesenchymal stem cell homing to kidneys in diabetic nephropathy rats," International Journal of Nanomedicine, vol. 9, no. 1, pp. 5639-5651, 2014.

[144] F. Ezquer, M. Giraud-Billoud, D. Carpio, F. Cabezas, P. Conget, and M. Ezquer, "Proregenerative microenvironment triggered by donor mesenchymal stem cells preserves renal function and structure in mice with severe diabetes mellitus," BioMed Research International, vol. 2015, Article ID 164703, 23 pages, 2015.
[145] A. H. Hamza, W. M. Al-Bishri, L. A. Damiati, and H. H. Ahmed, "Mesenchymal stem cells: a future experimental exploration for recession of diabetic nephropathy," Renal Failure, vol. 39, no. 1, pp. 67-76, 2017.

[146] J. A. Beckman, M. A. Creager, and P. Libby, "Diabetes and atherosclerosis: epidemiology, pathophysiology, and management," JAMA, vol. 287, no. 19, pp. 2570-2581, 2002.

[147] G. P. Fadini, M. Miorin, M. Facco et al., "Circulating endothelial progenitor cells are reduced in peripheral vascular complications of type 2 diabetes mellitus," Journal of the American College of Cardiology, vol. 45, no. 9, pp. 14491457, 2005.

[148] G. P. Fadini, S. Sartore, M. Albiero et al., "Number and function of endothelial progenitor cells as a marker of severity for diabetic vasculopathy," Arteriosclerosis, Thrombosis, and Vascular Biology, vol. 26, no. 9, pp. 2140-2146, 2006.

[149] C. Schmidt-Lucke, L. Rössig, S. Fichtlscherer et al., "Reduced number of circulating endothelial progenitor cells predicts future cardiovascular events: proof of concept for the clinical importance of endogenous vascular repair," Circulation, vol. 111, no. 22, pp. 2981-2987, 2005.

[150] C. Cheung and S. Sinha, "Human embryonic stem cellderived vascular smooth muscle cells in therapeutic neovascularisation," Journal of Molecular and Cellular Cardiology, vol. 51, no. 5, pp. 651-664, 2011.

[151] Y.-S. Yoon, S. Uchida, O. Masuo et al., "Progressive attenuation of myocardial vascular endothelial growth factor expression is a seminal event in diabetic cardiomyopathy: restoration of microvascular homeostasis and recovery of cardiac function in diabetic cardiomyopathy after replenishment of local vascular endothelial growth factor," Circulation, vol. 111, no. 16, pp. 2073-2085, 2005.

[152] B. Toffoli, S. Bernardi, R. Candido, S. Zacchigna, B. Fabris, and P. Secchiero, "TRAIL shows potential cardioprotective activity," Investigational New Drugs, vol. 30, no. 3, pp. 12571260, 2012.

[153] N. Zhang, J. Li, R. Luo, J. Jiang, and J.-A. Wang, "Bone marrow mesenchymal stem cells induce angiogenesis and attenuate the remodeling of diabetic cardiomyopathy," Experimental and clinical endocrinology \& diabetes, vol. 116, no. 02, pp. 104-111, 2008.

[154] C. E. Glass, P. K. Singal, and D. K. Singla, "Stem cells in the diabetic infarcted heart," Heart Failure Reviews, vol. 15, no. 6, pp. 581-588, 2010.

[155] J. Y. Min, Y. Yang, K. L. Converso et al., "Transplantation of embryonic stem cells improves cardiac function in postinfarcted rats," Journal of Applied Physiology, vol. 92, no. 1, pp. 288-296, 2002.

[156] T. J. Nelson, A. Martinez-Fernandez, S. Yamada, C. Perez-Terzic, Y. Ikeda, and A. Terzic, "Repair of acute myocardial infarction by human stemness factors induced pluripotent stem clells," Circulation, vol. 120, no. 5, pp. 408-416, 2009.

[157] V. Volarevic, N. Arsenijevic, M. L. Lukic, and M. Stojkovic, "Concise review: mesenchymal stem cell treatment of the complications of diabetes mellitus," Stem Cells, vol. 29, no. 1, pp. 5-10, 2011.

[158] X. Wang, T. Zhao, W. Huang et al., "Hsp20-engineered mesenchymal stem cells are resistant to oxidative stress via enhanced activation of Akt and increased secretion of growth factors," Stem Cells, vol. 27, no. 12, pp. 3021-3031, 2009. 
[159] A. H. Amin, Z. Y. Abd Elmageed, D. Nair et al., "Modified multipotent stromal cells with epidermal growth factor restore vasculogenesis and blood flow in ischemic hindlimb of type II diabetic mice," Laboratory Investigation, vol. 90, no. 7, pp. 985-996, 2010.

[160] V. Y. Suncion, E. Ghersin, J. E. Fishman et al., "Does transendocardial injection of mesenchymal stem cells improve myocardial function locally or globally?: an analysis from the percutaneous stem cell injection delivery effects on neomyogenesis (POSEIDON) randomized trial," Circulation Research, vol. 114, no. 8, pp. 1292-1301, 2014.

[161] H. Jiao, E. Xiao, and D. T. Graves, "Diabetes and Its effect on bone and fracture healing," Current Osteoporosis Reports, vol. 13, no. 5, pp. 327-335, 2015.

[162] R. Sanguineti, D. Storace, F. Monacelli, A. Federici, and P. Odetti, "Pentosidine effects on human osteoblasts in vitro," Annals of the New York Academy of Sciences, vol. 1126, no. 1, pp. 166-172, 2008.

[163] M. Alikhani, Z. Alikhani, C. Boyd et al., "Advanced glycation end products stimulate osteoblast apoptosis via the MAP kinase and cytosolic apoptotic pathways," Bone, vol. 40, no. 2, pp. 345-353, 2007.

[164] J. M. Kanczler and R. O. Oreffo, "Osteogenesis and angiogenesis: the potential for engineering bone," European Cells and Materials, vol. 15, pp. 100-114, 2008.

[165] M. Sun, J. Yang, J. Wang et al., "TNF- $\alpha$ is upregulated in T2DM patients with fracture and promotes the apoptosis of osteoblast cells in vitro in the presence of high glucose," Cytokine, vol. 80, pp. 35-42, 2016.

[166] C.-Y. Wang, H.-B. Yang, H.-S. Hsu et al., "Mesenchymal stem cell-conditioned medium facilitates angiogenesis and fracture healing in diabetic rats," Journal of Tissue Engineering and Regenerative Medicine, vol. 6, no. 7, pp. 559-569, 2012.

[167] N. Jaiswal, S. E. Haynesworth, A. I. Caplan, and S. P. Bruder, "Osteogenic differentiation of purified, culture-expanded human mesenchymal stem cells in vitro," Journal of Cellular Biochemistry, vol. 64, no. 2, pp. 295-312, 1997.

[168] S. P. Bruder, D. J. Fink, and A. I. Caplan, "Mesenchymal stem cells in bone development, bone repair, and skeletal regeneration therapy," Journal of Cellular Biochemistry, vol. 56, no. 3, pp. 283-294, 1994.

[169] B.-Y. Peng, C.-S. Chiou, N. K. Dubey et al., "Non-invasive in vivo molecular imaging of intra-articularly transplanted immortalized bone marrow stem cells for osteoarthritis treatment," Oncotarget, vol. 8, no. 57, pp. 97153-97164, 2017.

[170] S. C.-S. Hu and C.-C. E. Lan, "High-glucose environment disturbs the physiologic functions of keratinocytes: focusing on diabetic wound healing," Journal of Dermatological Science, vol. 84, no. 2, pp. 121-127, 2016.

[171] M. Albiero, L. Menegazzo, E. Boscaro, C. Agostini, A. Avogaro, and G. P. Fadini, "Defective recruitment, survival and proliferation of bone marrow-derived progenitor cells at sites of delayed diabetic wound healing in mice," Diabetologia, vol. 54, no. 4, pp. 945-953, 2011.

[172] A. Medina, P. G. Scott, A. Ghahary, and E. E. Tredget, "Pathophysiology of chronic nonhealing wounds," The Journal of Burn Care \& Rehabilitation, vol. 26, no. 4, pp. 306-319, 2005.

[173] M. Khamaisi, S. Katagiri, H. Keenan et al., "PKC $\Delta$ inhibition normalizes the wound-healing capacity of diabetic human fibroblasts," The Journal of Clinical Investigation, vol. 126, no. 3, pp. 837-853, 2016.
[174] D. S. Kwon, X. Gao, Y. B. Liu et al., "Treatment with bone marrow-derived stromal cells accelerates wound healing in diabetic rats," International Wound Journal, vol. 5, no. 3, pp. 453-463, 2008.

[175] M. Gill, S. Dias, K. Hattori et al., "Vascular trauma induces rapid but transient mobilization of VEGFR2 ${ }^{+} \mathrm{AC} 133^{+}$endothelial precursor cells," Circulation Research, vol. 88, no. 2, pp. 167-174, 2001.

[176] Y. Wu, R. C. H. Zhao, and E. E. Tredget, "Concise review: bone marrow-derived stem/progenitor cells in cutaneous repair and regeneration," Stem Cells, vol. 28, no. 5, pp. 905915, 2010.

[177] K. McFarlin, X. Gao, Y. B. Liu et al., "Bone marrow-derived mesenchymal stromal cells accelerate wound healing in the rat," Wound Repair and Regeneration, vol. 14, no. 4, pp. 471-478, 2006.

[178] E. Seo, J. S. Lim, J.-B. Jun, W. Choi, I.-S. Hong, and H.-S. Jun, "Exendin-4 in combination with adipose-derived stem cells promotes angiogenesis and improves diabetic wound healing," Journal of Translational Medicine, vol. 15, no. 1, p. 35, 2017.

[179] N. I. Hussien, N. Ebrahim, O. M. Mohammed, and D. Sabry, "Combination of obestatin and bone marrow mesenchymal stem cells prevents aggravation of endocrine pancreatic damage in type II diabetic rats," International Journal of Stem Cells, vol. 10, no. 2, pp. 129-143, 2017.

[180] X. Wang, C. Liu, Y. Xu et al., "Combination of mesenchymal stem cell injection with icariin for the treatment of diabetesassociated erectile dysfunction," PLoS One, vol. 12, no. 3, article e0174145, 2017.

[181] Y. Shi, L. Hou, F. Tang et al., "Inducing embryonic stem cells to differentiate into pancreatic $\beta$ cells by a novel three-step approach with activin A and all-trans retinoic Acid," Stem Cells, vol. 23, no. 5, pp. 656-662, 2005.

[182] K. A. Gallagher, Z.-J. Liu, M. Xiao et al., "Diabetic impairments in NO-mediated endothelial progenitor cell mobilization and homing are reversed by hyperoxia and SDF-1 $\alpha$," The Journal of Clinical Investigation, vol. 117, no. 5, pp. 1249-1259, 2007.

[183] M. Khan, S. Akhtar, S. Mohsin, S. N. Khan, and S. Riazuddin, "Growth factor preconditioning increases the function of diabetes-impaired mesenchymal stem cells," Stem Cells and Development, vol. 20, no. 1, pp. 67-75, 2011.

[184] I. Banerjee, N. Sharma, and M. Yarmush, "Impact of coculture on pancreatic differentiation of embryonic stem cells," Journal of Tissue Engineering and Regenerative Medicine, vol. 5, no. 4, pp. 313-323, 2011.

[185] G. Wang, Y. Li, Y. Wang et al., "Roles of the co-culture of human umbilical cord Wharton's jelly-derived mesenchymal stem cells with rat pancreatic cells in the treatment of rats with diabetes mellitus," Experimental and Therapeutic Medicine, vol. 8, no. 5, pp. 1389-1396, 2014.

[186] C. L. Rackham, P. C. Chagastelles, N. B. Nardi, A. C. HaugeEvans, P. M. Jones, and A. J. F. King, "Co-transplantation of mesenchymal stem cells maintains islet organisation and morphology in mice," Diabetologia, vol. 54, no. 5, pp. 1127 1135, 2011.

[187] N. Nagata, A. Iwanaga, K. Inoue, and Y. Tabata, "Co-culture of extracellular matrix suppresses the cell death of rat pancreatic islets," Journal of Biomaterials Science, Polymer Edition, vol. 13, no. 5, pp. 579-590, 2002. 
[188] J. Wang, H. Li, B. Li, Q. Gong, X. Chen, and Q. Wang, "Coculture of bone marrow stem cells and macrophages indicates intermediate mechanism between local inflammation and innate immune system in diabetic periodontitis," Experimental and Therapeutic Medicine, vol. 12, no. 2, pp. 567-572, 2016.

[189] A. Aiuti, S. Slavin, M. Aker et al., "Correction of ADA-SCID by stem cell gene therapy combined with nonmyeloablative conditioning," Science, vol. 296, no. 5577, pp. 2410-2413, 2002.

[190] S. Hacein-Bey-Abina, F. le Deist, F. Carlier et al., "Sustained correction of X-linked severe combined immunodeficiency by ex vivo gene therapy," The New England Journal of Medicine, vol. 346, no. 16, pp. 1185-1193, 2002.

[191] C. A. Gregory, D. J. Prockop, and J. L. Spees, "Non-hematopoietic bone marrow stem cells: molecular control of expansion and differentiation," Experimental Cell Research, vol. 306, no. 2, pp. 330-335, 2005.

[192] Y. Ma, A. Ramezani, R. Lewis, R. G. Hawley, and J. A. Thomson, "High-level sustained transgene expression in human embryonic stem cells using lentiviral vectors," Stem Cells, vol. 21, no. 1, pp. 111-117, 2003.

[193] O. Karnieli, Y. Izhar-Prato, S. Bulvik, and S. Efrat, "Generation of insulin-producing cells from human bone marrow mesenchymal stem cells by genetic manipulation," Stem Cells, vol. 25, no. 11, pp. 2837-2844, 2007.

[194] X. Qiu, C. Sun, W. Yu et al., "Combined strategy of mesenchymal stem cell injection with vascular endothelial growth factor gene therapy for the treatment of diabetes-associated erectile dysfunction," Journal of Ondrology, vol. 33, no. 1, pp. 37-44, 2012.

[195] B. Ouyang, X. Sun, D. Han et al., "Human urine-derived stem cells alone or genetically-modified with FGF2 improve type 2 diabetic erectile dysfunction in a rat model," PLoS One, vol. 9, no. 3, article e92825, 2014.

[196] K. Millette and S. Georgia, "Gene editing and human pluripotent stem cells: tools for advancing diabetes disease modeling and beta-cell development," Current Diabetes Reports, vol. 17, no. 11, p. 116, 2017.

[197] P. S. McGrath, C. L. Watson, C. Ingram, M. A. Helmrath, and J. M. Wells, "The basic helix-loop-helix transcription factor NEUROG3 is required for development of the human endocrine pancreas," Diabetes, vol. 64, no. 7, pp. 2497-2505, 2015.

[198] P. Lu, J. Chen, L. He et al., "Generating hypoimmunogenic human embryonic stem cells by the disruption of beta 2microglobulin," Stem Cell Reviews, vol. 9, no. 6, pp. 806813, 2013. 


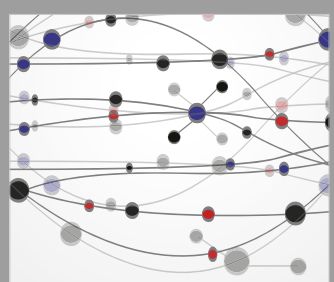

The Scientific World Journal
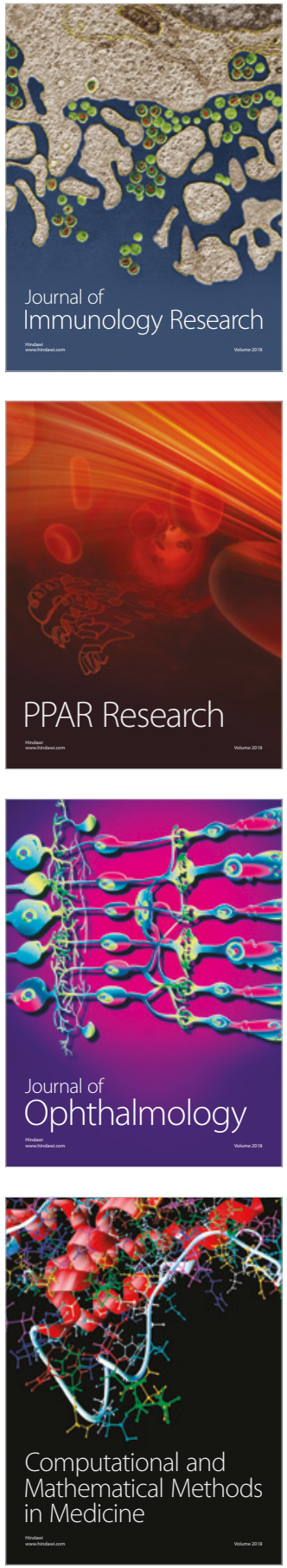

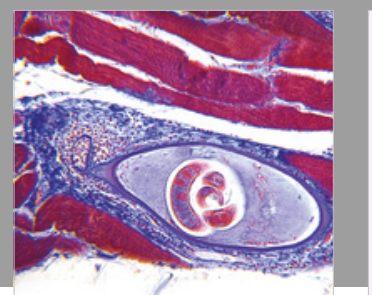

Gastroenterology Research and Practice

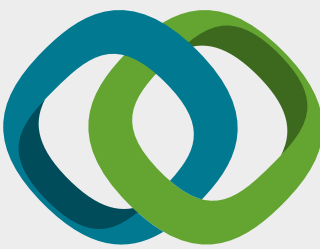

\section{Hindawi}

Submit your manuscripts at

www.hindawi.com
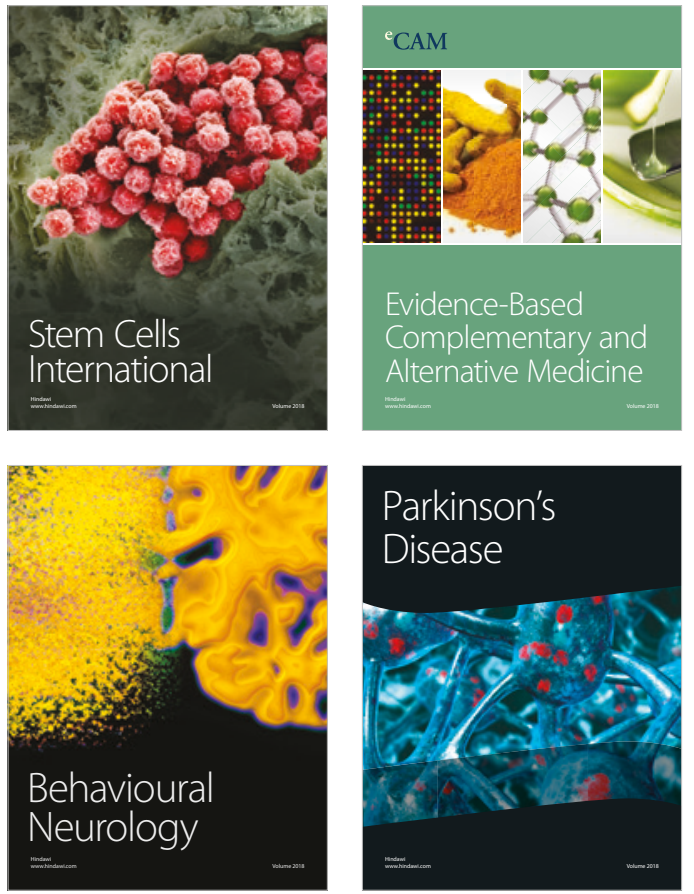

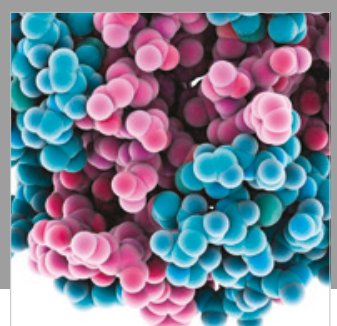

ournal of

Diabetes Research

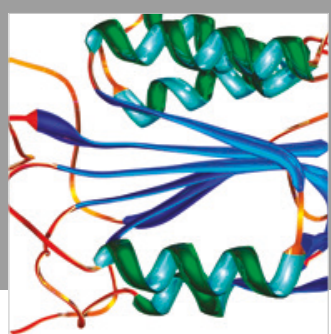

Disease Markers
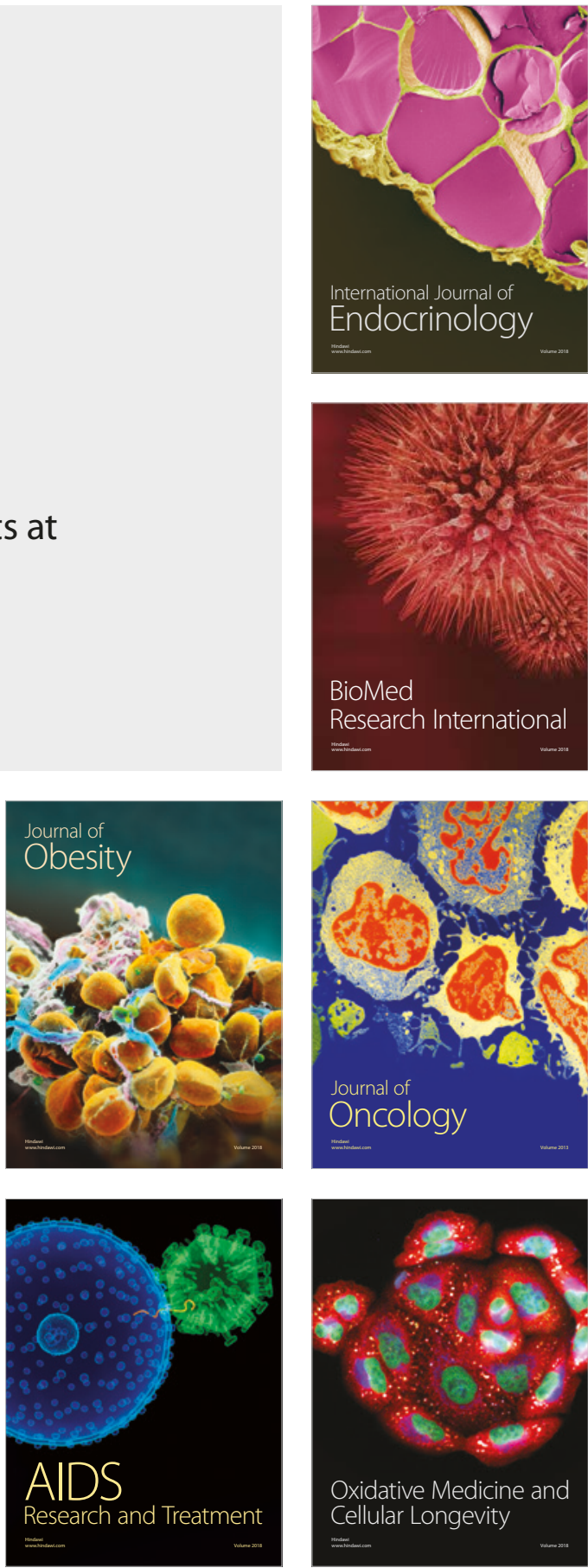